\title{
Economix
}

https://economix.fr/

\section{Taming Debt: Can GDP-Linked Bonds Do the Trick?}

Document de Travail

Working Paper 2020-13
Sarah Mouabbi Jean-Paul Renne Jean-Guillaume Sahuc 


\title{
TAMING DEBT: CAN GDP-LINKED BONDS DO THE TRICK?
}

\author{
SARAH MOUABBI, JEAN-PAUL RENNE AND JEAN-GUILLAUME SAHUC
}

\begin{abstract}
We study the debt-stabilizing properties of indexing debt to GDP using a consumption-based macro-finance model. Three results stand out: (i) GDP-linked bond prices would embed sizeable and timevarying risk premiums of about 40 basis points, (ii) for a fixed budget surplus, issuing GDP-linked bonds does not necessarily imply more beneficial debt-to-GDP ratios in the medium- to long-run, and (iii) the debt-stabilizing budget surplus is more predictable under such issuances at the expense of being higher on average. Our findings call into question the view that GDP-linked bonds tame debt.
\end{abstract}

JEL: H62, H63, E43, E44.

Keywords: GDP-linked bonds, debt stabilization, consumption-based model, term structure

\section{INTRODUCTION}

With the Great Recession, general government debt-to-GDP ratios in advanced economies increased considerably, from $71 \%$ in 2007 to $103 \%$ in 2019. Such large debt-to-GDP ratios can be a source of vulnerabilities, which amplify macroeconomic and financial shocks and thus increase the likelihood of a decline in economic activity. ${ }^{1}$ Discussions in policy circles suggest that indexing debt to GDP would reduce the severity of such an event by providing the government with an automatic stabilizer to its finance. By issuing state-contingent debt instruments, the government's burden of servicing its debt is higher in periods of strong economic growth, while payments are reduced in periods of economic downturn. In other words, if all of a country's public debt were indexed to GDP, one would expect the public debt-to-GDP ratio to be hedged against unforeseen changes in nominal GDP growth. However, other drivers, beyond economic growth, are key in determining the debt-to-GDP ratio, such as the quantity of debt issued across time, the bond prices associated with these issuances and other debtrelated variables. For instance, we expect that the price of a state-contingent asset, such as a GDP-linked

May 2020. S. Mouabbi: Banque de France, 31 rue Croix des Petits Champs, 75049 Paris, France (e-mail: sarah.mouabbi@banque-france.fr). J.-P. Renne: University of Lausanne, CH-1015 Lausanne, Switzerland (e-mail: jeanpaul.renne@unil.ch). J.-G. Sahuc: Banque de France, 31 rue Croix des Petits Champs, 75049 Paris, France (e-mail: jeanguillaume.sahuc@banque-france.fr). We are grateful to Sushant Acharya, Marco Bassetto, Christian Bayer, Christoph Boehm, Jeffrey R. Campbell, Antoine Camous, Ryan Chahrour, Harold Cole, Cynthia L. Doniger, Peter Feldhutter, Axelle Ferriere, Yuriy Gorodnichenko, Francois Gourio, Alexander Guembel, Stephane Guibaud, Patrick Kehoe, Robin Lumsdaine, Raoul Minetti, Francesco Pappada, Romain Ranciere, Pedro Teles, Dimitri Vayanos, Eric Van Wincoop, Francesco Zanetti, Ariel Zetlin-Jones, to seminar participants at the Federal Reserve Board, the ECB, McGill University, Agence France Trésor and to participants of the 2019 Asian Meeting of the Econometrics Society, the 2019 Melbourne Institute Macroeconomic Policy Meetings. The replication codes are available on our webpages. The views expressed in this paper are those of the authors and should under no circumstances be interpreted as reflecting those of the Banque de France or the Eurosystem.

${ }^{1}$ High debt levels can crowd out private capital investment and push the government to increase distortive taxes and to decrease its investment in order to facilitate repayment (Yared, 2019). Indeed, this explains why many countries have adopted fiscal rules to limit excessive debt buildups since the early 1990s. For instance, the United States has an expenditure rule that places caps on public spending, while the member states of the European Union are subject to Maastricht criteria which include staying within the limits on government deficit (3\% of GDP) and debt (60\% of GDP) (see Lledó et al., 2017). 
bond, is procyclical and therefore a government might need to issue more GDP-linked bonds to meet a given funding requirement in an adverse state of the world. Do GDP-linked bonds remain a relevant tool for the stabilization of debt once accounting for a wider set of determinants?

In this paper, we address this question by extending the representation of the debt-to-GDP process to allow for the issuance of any type of bond (conventional or GDP-linked) with any maturity. This generalization features several drivers of the debt-to-GDP process and notably requires information on the price dynamics of GDP-linked bonds, which is not directly observable given no large developed economy has ever issued them. ${ }^{2}$ To this end, we estimate an asset-pricing model that exploits observed macroeconomic and financial data that are informative about the pricing of GDP-linked bonds. Notably, we take advantage of the natural relationship between equity and GDP-linked bonds, as highlighted by Athanasoulis, Shiller, and Wincoop (1999). This relationship is reflected by a strong correlation between stock returns and GDP surprises, as illustrated in Panel (a) of Figure 1, where GDP surprises correspond to the unexpected part of (hypothetical) one-year GDP-linked bonds issued a year ago. Panel (b) of the same figure shows that the payoffs of conventional bonds are far less procyclical - and hence weakly correlated with stock returns - relative to GDP-linked bonds. ${ }^{3}$ Hence, to study the price dynamics of GDP-linked bonds, our model selection is driven by its ability to also capture the dynamics of stock returns. Specifically, we rely on the consumption-based model with habits à la Campbell and Cochrane (1999) and Wachter (2006) and extend it to include the term structure of hypothetical GDP-linked bond yields. This framework allows for time-varying investors' preferences (through habit persistence) and countercyclical risk premiums to successfully capture the joint dynamics of macroeconomic (GDP, consumption, inflation) and financial (stock returns, nominal and real yields of different maturities) data.

We further use this model to simulate debt-to-GDP ratios resulting from different public debt strategies involving all possible types of government bonds (conventional and GDP-linked bonds) and investigate their cost and risk implications. Specifically, we consider two extreme situations regarding the fiscal reaction function that differ in the way the primary budget surplus is determined. In the first exercise, the fiscal authority does not react to the debt-to-GDP ratio, and the primary budget surplus is set to a constant value. In the second one, the fiscal authority aims at perfectly stabilizing the debtto-GDP ratio. This strategy consists in setting the primary budget surplus to its debt-stabilizing value.

\footnotetext{
${ }^{2}$ Debt instruments indexed to GDP have already been issued in the past, but not by large advanced economies, and mainly in the context of debt restructuring. Examples include Brady bonds in the 90s (Costa Rica in 1990, Bulgaria in 1993 and Bosnia and Herzegovina in 1997). More recently, Argentina, Ukraine and Greece have issued GDP-linked warrants during their debt restructuring. In 2013, the Portuguese government issued small-denomination bonds to domestic savers with additional payouts tied to GDP. Importantly, all these instruments did not provide symmetrical payoffs; that is, they promised larger payoffs if certain growth thresholds or other payment milestones were met, but no lower payoffs if the economy of the issuing government fell into recession. This limits the relevance of these past experiments when it comes to assessing the potential issuance of GDP-linked bonds with symmetrical payoffs by large advanced economies. Note that the symmetric indexation underlies the recent GDP-linked bonds proposals.

${ }^{3}$ The close relationship between equity and GDP-linked bonds is implicitly reckoned in asset-pricing studies where shares are represented by claims on future consumption (e.g. Abel, 1999; Campbell and Cochrane, 1999; Campbell, 2003; Wachter, 2006; Seo and Wachter, 2018): if one assumes a unitary elasticity between consumption and GDP, these models then imply that a share is the exact same asset as a perpetual coupon-paying GDP-LB.
} 
Papers on optimal public debt management are often based on similar budget smoothing arguments, i.e. stabilizing or targeting the level of debt, see for instance Faraglia, Marcet, and Scott (2008). However, this strand of the literature is known to struggle in providing practically-implementable strategies (Faraglia, Marcet, and Scott, 2010). In our setup, we abstract from any normative recommendations (as in Bohn, 1990; Angeletos, 2002; Buera and Nicolini, 2004), and rather assess the implications of using different debt instruments in stabilizing the debt-to-GDP ratio.

Three results stand out from our analysis. First, GDP-linked bond prices would embed sizable and time-varying risk premiums, estimated at about 40 basis points along the maturity spectrum, as investors require an additional compensation for holding them. Second, for a fixed budget surplus, issuing GDP-linked bonds instead of conventional ones does not necessarily imply more beneficial debt-toGDP ratios in the medium to long run. Third, the debt-stabilizing budget surplus is more predictable under GDP-linked bond issuances at the expense of being higher on average. Hence, our findings call into question the view that GDP-linked bonds tame debt.

Several papers explore the potential benefits of GDP-linked bond issuances. For instance, Borensztein and Mauro (2004) simulate the effects of GDP-linked bonds under different assumptions about fiscal policy reaction functions and their output effects, and find that they could substantially reduce the likelihood of debt-to-GDP paths becoming explosive. Similarly, using a simple method for pricing GDP-linked bonds, Chamon and Mauro (2006) show that such bonds can help in improving debt structures and thereby reduce vulnerabilities and the degree of procyclicality in fiscal policies. Their method relies on extracting information from observed prices of plain-vanilla bonds and applying that information to the case of GDP-linked bonds through a Monte-Carlo exercise. More recently, Blanchard, Mauro, and Acalin (2016) explain that introducing GDP-linked bonds on a large scale in advanced economies could substantially reduce tail risks associated with explosive debt paths. They further note that such bonds may also require a premium, which could (partially) offset the first effect. While, these papers provide interesting insights on GDP-linked bonds, they hinge on strict assumptions: (i) interest rates are constant and (ii) the government only issues short-term bonds. In practice, interest rates vary over time and most sovereign bond issuances are in the form of medium to long-term bonds. These two facts cannot be disregarded to assess the stabilizing potential of a novel class of bonds. Indeed, the variability of interest rates is crucial when analyzing state-contingent bonds. This is because they provide lower payoffs to the bondholders during economic downturns, and thus, GDP-linked bonds would trade at a discount in comparison with conventional ones. The additional excess return that investors require to hold GDP-linked bonds generates, on average, a higher funding cost for the government. Moreover, when long-term GDP-linked bonds are issued, new issuances will follow before the maturity of these bonds comes to term. Given that the final debt-to-GDP ratio depends on the prices of future issuances, which are unknown, the hedging benefits resulting from GDP-linked bond issuances tend to wane with the horizon. 
FIGURE 1. Realized vs expected real payoffs of one-year bonds with unit face value

Panel (a) - GDP Surprises and Stock Returns

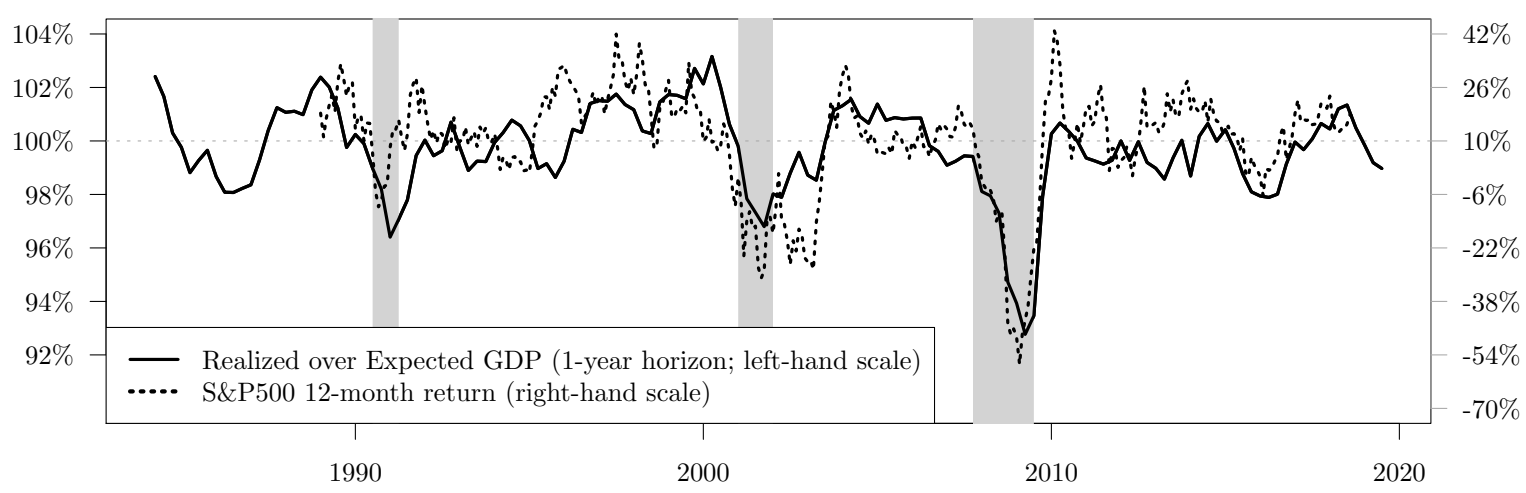

Panel (b) - Realized-over-Expected Real Payoff

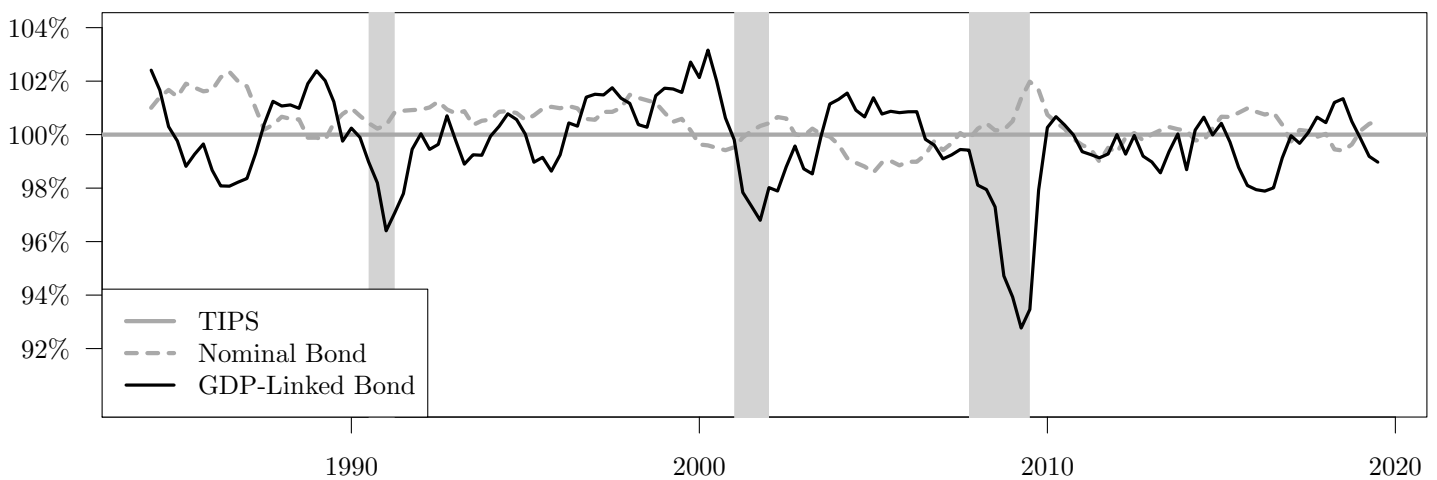

Note: Panel (a) shows that GDP surprises are highly correlated with the one-year returns of the S\&P500 stock price index. The Realized-over-Expected GDP ratio is defined by $\left(1+y_{t-4, t}+\pi_{t-4, t}\right) /\left(1+\mathbb{E}_{t-4}\left[y_{t-4, t}+\pi_{t-4, t}\right]\right)$, where $\pi_{t-4, t}$ and $y_{t-4, t}$ respectively denote inflation and real GDP growth rates between quarters $t-4$ and $t$. The (model-free) computation of this ratio involves expectations stemming from the Survey of Professional Forecasters conducted by the Philadelphia Fed. Panel (b) displays (model-free) realized-versus-expected ratios of payoffs associated with three types of one-year bonds: a nominal bond, an inflation-linked bond (TIPS) and a (hypothetical) GDP-linked bond. Based on the definition of a TIPS, the realized real payoff of such a bond is equal to its expectation, which implies a constant ratio of $100 \%$ for this type of bond. For the nominal bond, this ratio is computed as $\left(1+\mathbb{E}_{t-4}\left[\pi_{t-4, t}\right]\right) /\left(1+\pi_{t-4, t}\right)$. For a GDP-linked bond, this ratio is equal to the Realized-over-Expected GDP ratio shown in Panel (a). Shaded areas indicate NBER recession periods.

The remainder of the paper is organized as follows. Section 2 defines the three bonds we consider in our analysis (nominal, inflation-linked and GDP-linked) and their respective yields-to-maturity. This section also characterizes the debt dynamics under the issuance of these three types bonds. Section 3 describes our model and estimation strategy. Section 4 presents empirical results of the effects of the issuance of GDP-linked bonds on Debt-to-GDP ratios. Section 5 provides a discussion of other important considerations and Section 6 concludes. The Appendix encloses pricing formulas and technical results. An Online Appendix gathers proofs.

\section{ISSUED BONDS AND DEBT DYNAMICS}

In this section, we define GDP-linked bonds (GDP-LBs) and study their influence on debt dynamics. To highlight the properties of GDP-LBs, we contrast them against two standard instruments, namely 
nominal and inflation-linked bonds. Subsection 2.1 details the payoffs stemming from each type of bonds and defines their respective yields-to-maturity. Subsection 2.2 exploits yields-to-maturities to derive the debt accumulation process. Subsection 2.3 shows how the standard law of motion of the debt-to-GDP ratio can be extended to the general case where the government issues any type of bonds. Importantly, the content of the present section is not model dependent and could be used in the context of any modeling framework.

\subsection{Bonds}

Without loss of generality, we only consider zero-coupon bonds. ${ }^{4}$ Let us denote by $i_{t, h}, r_{t, h}$ and $r_{t, h}^{*}$, the continuously-compounded yields-to-maturity respectively associated with zero-coupon nominal, inflation-linked and GDP-linked bonds with residual maturities of $h$ periods. The definition of any type of yield is mostly conventional: a yield unequivocally relates the bond price (as of date $t$ ) to expected payoffs (at date $t+h$ ).

In the case of nominal and inflation-linked bonds, future payoffs are trivial. For nominal bonds with a face value of 1 , the expected future nominal payoff (settled at date $t+h$ ) corresponds to one unit of currency as of date $t+h$. Similarly, the expected future real payoff (also settled at date $t+h$ ) of an inflation-linked bond of face value of 1 is equal to one unit of currency as of date $t$. This corresponds, in nominal terms, to $\exp \left(h \pi_{t, t+h}\right)$ units of currency as of date $t+h$, with $h \pi_{t, t+h}$ denoting the inflation rate between dates $t$ and $t+h \cdot{ }^{5}$ Note that, for a nominal bond, the expected nominal maturity payoff as of date $t$ is deterministic. However, this is not the case for its real payoff, given inflation between $t$ and $t+h$ is uncertain as of date $t$. Vice versa for an inflation-linked bond, the real payoff is deterministic while the nominal one is uncertain as of date $t$. The fact that nominal and inflation-linked bonds respectively feature predetermined nominal and real payoffs is key for the definition of their (nominal and real) yields-to-maturity. The nominal yield-to-maturity $i_{t, h}$ is based on the logarithm of the ratio between the nominal face value of a nominal bond (which is 1 ) and its current price $P_{t, h}^{n}$, that is

$$
i_{t, h} \equiv \frac{1}{h} \log \left(\frac{1}{P_{t, h}^{n}}\right),
$$

and the real yield-to-maturity $r_{t, h}$ is based on the logarithm of the ratio between the real face value of an inflation-linked bond (which is 1) and its current price $P_{t, h^{\prime}}^{r}$ that is

$$
r_{t, h} \equiv \frac{1}{h} \log \left(\frac{1}{P_{t, h}^{r}}\right) \text {. }
$$

\footnotetext{
${ }^{4}$ Coupon-bearing bonds can always be replicated using a combination of zero-coupon bonds.

${ }^{5}$ In practice, the nominal payoff of inflation-linked bonds is indexed to lagged realized inflation (typically with a lag of a few months). Refer to Section I of Gürkaynak, Sack, and Wright (2010) for an illustration on US Treasury Inflation-Protected Securities (TIPS). In our setup, we abstract from the so-called indexation lag. To the extent that the pricing influence of this feature mainly concerns short-dated bonds, our results would not be affected had it been taken into account.
} 
Such standard definitions of yields-to-maturity are not replicable for bonds whose (real or nominal) payoffs are not known as of date $t$, as is the case for GDP-LBs, due to their state-contingent nature. All the more, pure GDP-LBs have not been issued for the time being, hence there is no established convention regarding the definition of their associated yields-to-maturity. We thus propose a definition below.

To do so, we first need to establish the exact payoff of such a bond. Following the literature, we consider payoffs that are linearly and unitarily indexed to nominal GDP growth between $t$ and $t+h$. Consequently, the nominal maturity payoff of a GDP-linked bond issued at date $t$ is of the form:

$$
\alpha \exp \left(h\left[y_{t, t+h}+\pi_{t, t+h}\right]\right),
$$

where $h y_{t, t+h}$ denotes the log real growth between dates $t$ and $t+h$ (i.e. $\exp \left(h y_{t, t+h}\right)=Y_{t+h} / Y_{t}$ where $Y_{t}$ is real GDP at date $t$ ). While the coefficient $\alpha$ can be set to any value, we have to make it precise in order to define a "unit face value"- a notion needed to define the yield-to-maturity. In what follows, a "unit face value" maturity- $h$ GDP-linked bond issued at date $t$ is defined as a bond characterized by $\alpha=1 / \mathbb{E}_{t}\left[\exp \left(h y_{t, t+h}\right)\right]$, where $\mathbb{E}_{t}$ denotes the expectation operator conditional on information at date $t$. This bond provides the following real payoff to its bondholder at date $t+h$ :

$$
\frac{\exp \left(h y_{t, t+h}\right)}{\mathbb{E}_{t}\left[\exp \left(h y_{t, t+h}\right)\right]} \text {. }
$$

It is important to note that, as of date $t$, the expected real maturity payoff of this bond is one. In other words, this bond has a "unit face value".

We now proceed to defining the yield-to-maturity of a GDP-linked bond. Inspired by Eq. (2), the date- $t$ yield-to-maturity $r_{t, h}^{*}$ of a maturity- $h$ GDP-linked bond is defined as the time-to-maturity-adjusted logarithm of the ratio between the expected real maturity payoff and the current bond price $P_{t, h}^{*}$ :

$$
r_{t, h}^{*} \equiv \frac{1}{h} \log \left(\frac{1}{P_{t, h}^{*}}\right) .
$$

While the definition of this yield is conventional, its bond price is not once its payoff is defined as in Eq. (3). However, our definition admits two convenient features. First, it is easily seen that $r_{t, h}^{*}$ can be expressed as the date-t-expected log real return of a GDP-linked bond of maturity $h$ issued at time $t$. Such a return can be expressed as:

$$
\frac{1}{h} \log \left\{\mathbb{E}_{t}\left(\frac{\exp \left(h y_{t, t+h}\right)}{\mathbb{E}_{t}\left[\exp \left(h y_{t, t+h}\right)\right]}\right) / P_{t, h}^{*}\right\},
$$

which is also equal to the right-hand-side of Eq. (4).

Second, if investors were risk-neutral, then GDP-linked bond yields $r_{t, h}^{*}$ would coincide with the inflation-linked bond yields $r_{t, h}$, given that both rates are expressed in real terms. Specifically, Eq. (3) shows that the expected real maturity payoff of a unit face value GDP-linked bond is one, as is the case 
for a unit face value inflation-linked bond. Hence, risk-neutral agents would be indifferent between holding either bonds, implying $P_{t, h}^{*}=P_{t, h}^{r}$ and, further, $r_{t, h}^{*}=r_{t, h}$ (using Eqs. 2 and 4).

As explained above, this definition relies on the specification of the payoff of a unit face value GDPlinked bond, in the sense that $r_{t, h}^{*}$ is defined through the price $P_{t, h}^{*}$ of a bond whose payoff is given by Eq. (3). However, the latter payoff contains a term, $\mathbb{E}_{t}\left[\exp \left(h y_{t, t+h}\right)\right]$, that is never perfectly observed in practice. One can circumvent this issue by setting a convention: the expectation at time $t$ of GDP growth between $t$ and $t+h$ could be proxied using survey-data such as the Survey of Professional Forecasters conducted by the Federal Reserve, or even using a smoothed average of past GDP growth rates.

\subsection{The accounting of public debt}

Yields-to-maturity have important implications on public debt accounting. Specifically, they are involved in the recording of accrued interests, which play a crucial role in the determination of the outstanding debt. International statistical standards advocate for the use of the concept of "nominal valuation of debt securities", where the outstanding debt reflects the sum of funds originally advanced (the issue price), plus any subsequent advances, less any repayments, plus any accrued interest (see International Monetary Fund, Bank for International Settlements and European Central Bank, 2015, notably 5.51 on p. 39, 5.55 on p. 40). ${ }^{6}$ According to the System of National Accounts (2008, paragraph 7.113), the accrued interest is the amount that issuers of debt securities become liable to pay over a given period of time without reducing the outstanding principal.

Let us illustrate the rationale behind this accounting convention using the case of a 10-year nominal zero-coupon bond. Consider that the government issues such a bond in year $t$, with issuance proceeds equal to 100. Assume further that, at issuance, the yield-to-maturity $i_{t, h}$ is equal to $4 \%$ per annum. Under nominal valuation, the recorded debt is 100 in year $t, 100 \times \exp (0.04) \approx 104$ in year $t+1, \ldots$, and $100 \times \exp (10 \times 0.04) \approx 149$ in year $t+10$. It is important to note that, from $t+1$ to $t+9$, recorded debt increases even if the government does not pay interests. However, the increase is consistent with the idea that the government gets increasingly liable during this period. In other words, if accrued interests were not accounted for, the recorded outstanding debt would artificially remain at 100 between $t$ and $t+9$, and would artificially jump to 149 at $t+10 .^{7}$

Similarly, this accounting convention translates to inflation-linked bonds as follows. Consider a 10year inflation-linked zero-coupon bond issued at a real interest rate of $2.5 \%$ and assume that the issuance proceeds are also equal to 100 . If inflation is of $1 \%$ between $t$ and $t+1$, then the outstanding debt is of $100 \exp (0.025+0.01)$ at date $t+1$. Moreover, if inflation is of $3 \%$ between dates $t+1$ and

\footnotetext{
${ }^{6}$ This document is available at http://www. bis. org/publ/othp23.pdf.

${ }^{7}$ This convention follows the "debtor approach", which uses issuance yields. An alternative consists in recording the debt at its (secondary) market value on every date between $t$ and $t+10$ - an approach referred to as the "creditor approach". Intuitively, under the latter approach, the debt outstanding corresponds to the amount that the government would have to pay on the secondary market to get rid of its marketable-debt-related commitments. However, it is not the one retained in international public debt accounting standards (see 5.56 to 5.58, p. 40 of International Monetary Fund, Bank for International Settlements and European Central Bank, 2015). See also Wright and Joisce (2001).
} 
$t+2$, then the debt is of $100 \exp (\{0.025+0.01\}+\{0.025+0.03\})$ in year $t+2$, and so on and so forth. Therefore, the recorded debt increases from $t$ to $t+9$, despite the fact that the government does not pay any interest until $t+10 .^{8}$

What precedes has important implications on the assessment of the indebtedness of a government. As suggested by the previous stylized zero-coupon examples, an inappropriate recording of accrued interest may result in a substantial undervaluation of government liabilities (at least for some time). Arguably, this contributed to trigger, or at least to accelerate, the Greek sovereign debt crisis in 2010 (Ball and Pflugrath, 2012; Serafeim, 2015; Soll, 2015). Prior to the crisis, Greece had not adopted accrual accounting, hence, its reported debt was undervalued with respect to fair-value accounting practices. In late 2009, the Greek government admitted that, under the standard accounting framework, its debt would be much higher. This revision acted as a wake-up call and gave rise to a self-fulfilling lack of international confidence in Greece's ability to repay its sovereign debt. ${ }^{9}$

TABLE 1. Characteristics of zero-coupon debt instruments

\begin{tabular}{lcc}
\hline Instrument & $h$-period yield (at issuance) & Accrued nominal value at date $t+k$ \\
\hline Nominal bond & $i_{t, h}$ & $\exp \left(k i_{t, h}\right)$ \\
Inflation-linked bond & $r_{t, h}$ & $\exp \left(k\left[r_{t, h}+\pi_{t, t+k}\right]\right)$ \\
GDP-linked bond & $r_{t, h}^{*}$ & $\exp \left(k\left[r_{t, h}^{*}+\left(y_{t, t+k}-y_{t, h}^{e}\right)+\pi_{t, t+k}\right]\right)$ \\
\hline
\end{tabular}

Note: The last column reports the outstanding debt, recorded at date $t+k$, resulting from the issuance of a zero-coupon bond (nominal, inflation-linked, or GDP-linked) at date $t$. This issuance provides unitary proceeds to the government at the issuance date $t$. The accrued amounts are expressed in nominal terms. We use the notation: $y_{t, h}^{e}=\frac{1}{h} \log \mathbb{E}_{t}\left[\exp \left(y_{t, t+h}\right)\right]$; where $y_{t, h}^{e}$ denotes the expected annualized continuously-compounded GDP growth rate between $t$ and $t+h$ (expected as of date $t$ ). We also denote by $\pi_{t, t+h}$ the realized annualized continuously-compounded inflation rate between $t$ and $t+h$. At date $t+h$, the accrued value is equal to the amount repaid by the issuer to the bondholder.

Using the above-mentioned accounting convention, we can provide the accrued debt generated by the issuances of the three types of bonds defined in Subsection 2.1. Table 1 reports the accrued nominal debt generated by each issuance between $t$ (issuance date) and $t+h$ (maturity date). In the case of GDP-LBs, we make use of the following notation: $\exp \left(h y_{t, h}^{e}\right)=\mathbb{E}_{t}\left[\exp \left(h y_{t, t+h}\right)\right]$.

\subsection{Debt accumulation process}

Assuming that the government only issues short-term nominal bonds, the dynamics of the nominal outstanding debt $D_{t}$, observed at the end of date $t$, is given by

$$
D_{t}=D_{t-1} \exp \left(i_{t-1,1}\right)-B S_{t}
$$

where $B S_{t}$ is the primary budget surplus at date $t$. Let us denote by small capitals a variable normalized by nominal GDP $\left(Y_{t} P_{t}\right)$, where $Y_{t}$ is the real GDP and $P_{t}$ is the GDP deflator. Eq. (5) can therefore be

\footnotetext{
${ }^{8}$ See Tables A.1.3 and A.1.4, p. 111 in Annex 1 of International Monetary Fund, Bank for International Settlements and European Central Bank (2015).

${ }^{9}$ This was primarily explained by out-of-the-money swaps that the Greek government contracted with major investment banks in the early 2000s. These out-of-the-money swaps were actually disguised loans. This European public accounting problem was subsequently addressed by Eurostat (2016).
} 
written in terms of the debt-to-GDP ratio, as follows:

$$
d_{t}=\exp \left(i_{t-1,1}-y_{t-1, t}-\pi_{t-1, t}\right) d_{t-1}-b s_{t}
$$

where $d_{t}=D_{t} /\left(Y_{t} P_{t}\right)$ and $b s_{t}=B S_{t} /\left(Y_{t} P_{t}\right)$.

This equation is often used in the GDP-LB literature, given it is always assumed that the government only issues short-term debt. However, this assumption being restrictive, we extend the representation of the dynamics of debt to allow for issuances of any maturity and bond type (nominal, inflation-linked, and GDP-linked bonds). This generalization necessitates the introduction of additional debt-related variables. Specifically, the outstanding debt depends on its own lagged values and also on the types and maturities of the debt instruments that have been issued in the past. At date $t$, the government issues the following amount of new debt:

$$
I_{t}=\sum_{h=1}^{H} I_{t, h}^{n}+I_{t, h}^{r}+I_{t, h}^{*}
$$

where $I_{t, h}^{n} I_{t, h}^{r}$ and $I_{t, h}^{*}$ are the amounts issued in the form of maturity- $h$ nominal, real and GDP-linked bonds, respectively, and where $H$ is the largest maturity of issued bonds. Using the information reported in the last column of Table 1 to account for the accruing of past issuances, we obtain the following expression for $D_{t}$ :

$$
D_{t}=I_{t}+\underbrace{\sum_{h=1}^{H} \sum_{k=1}^{h-1} I_{t-k, h}^{n} e^{k i_{t-k, h}}+I_{t-k, h}^{r} e^{k\left[r_{t-k, h}+\pi_{t-k, t}\right]}+I_{t-k, h}^{*} e^{k\left[r_{t-k, h}^{*}+\left(y_{t-k, t}-y_{t-k, h}^{e}\right)+\pi_{t-k, t}\right]}}_{\text {accrued (and non-repaid) debt }} .
$$

This expression can be re-written as follows (see Appendix $C$ for further details): ${ }^{10}$

$$
\begin{aligned}
& b s_{t}+d_{t}-d_{t-1} \\
= & \sum_{h=1}^{H} \sum_{k=1}^{h} i s s_{t-k, h}^{n}\left[e^{k\left(i_{t-k, h}-y_{t-k, t}-\pi_{t-k, t}\right)}-e^{(k-1)\left(i_{t-k, h}-y_{t-k, t-1}-\pi_{t-k, t-1}\right)}\right]+ \\
& \sum_{h=1}^{H} \sum_{k=1}^{h} i s s_{t-k, h}^{r}\left[e^{k\left(r_{t-k, h}-y_{t-k, t}\right)}-e^{(k-1)\left(r_{t-k, h}-y_{t-k, t-1}\right)}\right]+ \\
& \sum_{h=1}^{H} \sum_{k=1}^{h} i s s_{t-k, h}^{*}\left[e^{k\left(r_{t-k, h}^{*}-y_{t-k, h}^{e}\right)}-e^{(k-1)\left(r_{t-k, h}^{*}-y_{t-k, h}^{e}\right)}\right]
\end{aligned}
$$

where $i s s_{t, k}^{n}=I_{t, k}^{n} /\left(Y_{t} P_{t}\right), i s s_{t, k}^{r}=I_{t, k}^{r} /\left(Y_{t} P_{t}\right)$, and iss $s_{t, k}^{*}=I_{t, k}^{*} /\left(Y_{t} P_{t}\right)$.

It can be noted that the right-hand side of Eq. (9) corresponds to the value of the budget surplus $b s_{t}$ that implies no change in the debt-to-GDP ratio between $t-1$ and $t$. We refer to this particular value as the "debt-stabilizing budget surplus" (DSBS). Note that the DSBS value at time $t$ does not depend on the choice of the type of bonds issued at the same date $\left(i s s_{t, h}^{*}, i s s_{t, h}^{r}\right.$ and $i s s_{t, h}^{n}$ do not appear on the right-hand side of Eq. 9).

\footnotetext{
${ }^{10}$ Naturally, this equation boils down to Eq. (6) when only short-term nominal bonds are issued.
} 


\section{MODEL}

In this section, we introduce a model to analyze the debt-to-GDP ratio dynamics resulting from the issuance of different types of debt instruments. As shown above, the required framework needs to capture the joint fluctuations of bond prices, real GDP and inflation. To this end, we use an off-theshelf consumption-based model with habits à la Campbell and Cochrane (1999) and Wachter (2006) and extend it to include the term structure of hypothetical GDP-linked bond yields. This setup features time-varying investors' preferences (through habit persistence) and is able to produce realistic risk premiums for both bonds and stocks. Our chosen framework is able to easily reproduce an upwardsloping term structure of real (TIPS) rates, as observed in the data. In contrast, most structural models mechanically generate a downward-sloping term structure of real rates. ${ }^{11}$ The fact that our model delivers reliable average interest rates is a desirable characteristic since our study hinges on the average funding costs underlying the issuance of different types of bonds.

Subsections 3.1 and 3.2 describe the model. Subsections 3.3 details the data used in the empirical analysis and 3.4 presents how parameter values are set. Model parameters are determined so as to reproduce first and second moments associated with macroeconomic variables, nominal and real bond yields, as well as equity-related prices and ratios. Importantly, the feasibility of this strategy relies on various quasi-analytical pricing formulas (see Appendix B), which are based on an approximated state dynamics (see Appendix A). ${ }^{12}$

\subsection{Macroeconomic dynamics}

We consider a closed economy populated by an infinity of identical investors whose consumption level at time $t$ is denoted by $C_{t}$. The logarithm of consumption, denoted by $c_{t}$, evolves according to:

$$
c_{t}=c_{t-1}+g_{c}+v_{t}
$$

where $g_{c}$ is the average consumption growth and $v_{t}$ is an i.i.d. zero-mean shock whose cumulative distribution function (c.d.f.) is denoted by $f$. Real GDP growth, defined as $\Delta y_{t}=\log \left(Y_{t} / Y_{t-1}\right)$, and inflation, defined as $\pi_{t}=\log \left(P_{t} / P_{t-1}\right)$, follow the processes:

$$
\begin{aligned}
\Delta y_{t} & =g_{y}+\rho_{y} v_{t}+\varepsilon_{t}^{y} \\
\pi_{t} & =(1-\psi) \bar{\pi}+\psi \pi_{t-1}+\rho_{\pi} v_{t}+\varepsilon_{t}^{\pi},
\end{aligned}
$$

where $g_{y}$ is the average GDP growth, $\bar{\pi}$ is the average inflation, $\varepsilon_{t}^{y} \sim$ i.i.d. $\mathcal{N}\left(0, \sigma_{y}^{2}\right), \varepsilon_{t}^{\pi} \sim$ i.i.d. $\mathcal{N}\left(0, \sigma_{\pi}^{2}\right)$, and $\psi$ is a smoothing parameter. If $\rho_{y} \neq 0$ (respectively $\rho_{\pi} \neq 0$ ), consumption and GDP growth (resp. inflation) are correlated.

\footnotetext{
${ }^{11}$ See e.g. Piazzesi and Schneider (2007), in particular their Subsections 3.4 and 3.5.

${ }^{12}$ Consistent with the literature, our formulas rely on a discretization of the state space. However, unlike most studies resorting to such grid-based approaches (e.g. Wachter, 2005), we propose explicit formulas for all considered moments by exploiting the Markov-switching representation of the state dynamics (see Appendix A.1). Interestingly, this provides us with the approximate risk-neutral dynamics of our variables of interest.
} 


\subsection{Agents' preferences}

Following Campbell and Cochrane (1999) and Wachter (2006), each investor has the following utility over consumption:

$$
\mathbb{E}_{t}\left(\sum_{h=0}^{+\infty} \delta^{h} \frac{\left(C_{t+h}-X_{t+h}\right)^{1-\gamma}-1}{1-\gamma}\right),
$$

where $X_{t}$ is the level of habit (a reference point), $\delta$ is the subjective discount factor, $\gamma$ is the utility curvature. Habit is defined through the dynamics of consumption surplus $S_{t}$, as follows:

$$
S_{t} \equiv \frac{\widetilde{C}_{t}-X_{t}}{\widetilde{C}_{t}}
$$

where $\widetilde{C}_{t}$ denotes average consumption. Habits are external and therefore each investor's habit is determined by everyone else's consumption. This simplifies the analysis given that current consumption is not affected by future habit. In equilibrium, identical investors choose the same level of consumption, and hence $\widetilde{C}_{t}=C_{t}$. Based on these assumptions, the stochastic discount factor between $t$ and $t+1$ is given by:

$$
M_{t, t+1}=\delta\left(\frac{S_{t+1}}{S_{t}} \frac{C_{t+1}}{C_{t}}\right)^{-\gamma}
$$

We now specify the joint dynamics of $S_{t}$ and $C_{t}$. Since surplus consumption $S_{t}$ is strictly positive, its dynamics can be defined through its logarithm $s_{t}$, given by: ${ }^{13}$

$$
\begin{aligned}
s_{t+1} & =(1-\phi) \bar{s}+\phi s_{t}+\lambda\left(s_{t}\right)\left(c_{t+1}-\mathbb{E}_{t}\left(c_{t+1}\right)\right) \\
& =(1-\phi) \bar{s}+\phi s_{t}+\lambda\left(s_{t}\right) v_{t+1} \\
\lambda\left(s_{t}\right) & = \begin{cases}\frac{1}{\exp (\bar{s})} \sqrt{1-2\left(s_{t}-\bar{s}\right)}-1 & \text { if } s_{t} \leq s_{\max } \\
0 & \text { otherwise }\end{cases}
\end{aligned}
$$

where $\phi$ controls the peristence of habit, $s_{\max }=\bar{s}+\frac{1}{2}\left(1-\exp (\bar{s})^{2}\right)$, which ensures that $\lambda\left(s_{t}\right) \geq 0$, and with

$$
\bar{s}=\log \left(\sqrt{\operatorname{Var}(v) \frac{\gamma}{1-\phi-b / \gamma}}\right) .
$$

To calibrate the model, we make use of stock return moments. To this purpose, we complement our model with the specification of real dividends Div $_{t}$, which have the following law of motion:

$$
\log \operatorname{Div}_{t}=\log \operatorname{Div}_{t-1}+\overline{d i v}+\rho_{d} v_{t}+\varepsilon_{t}^{d}
$$

where $\overline{d i v}$ is the average of the logarithm of real dividends and $\varepsilon_{t}^{d} \sim$ i.i.d. $\mathcal{N}\left(0, \sigma_{d}^{2}\right)$. The resulting stock return formulas are detailed in Appendix B.4.

\footnotetext{
${ }^{13}$ Using the notation $x_{t}=\log \left(X_{t}\right)$, Eq. (16) implies that $\frac{d x_{t+1}}{d c_{t+1}}=1-\frac{\lambda\left(s_{t}\right)}{\exp \left(-s_{t}\right)-1}$. As shown by Eq. (17), $\lambda(\bar{s})=\frac{1}{\exp (\bar{s})}-1$, therefore $\frac{d x_{t+1}}{d c_{t+1}}=0$. This implies that habit is predetermined at the steady state.
} 
We also provide pricing formulas for inflation-linked, nominal and GDP-linked bonds of any maturity in Appendices B.1, B.2 and B.3, respectively.

\subsection{Data}

We use US data spanning the period from 1985Q1 to 2018Q1. Macroeconomic data comprise real GDP, consumption and inflation, and are extracted from the FRED database (Federal Reserve Bank of St. Louis). Consumption encompasses non-durables and services, and is deflated by the GDP deflator. Inflation is the log growth rate of the GDP deflator. Financial data include nominal and real yields at different maturities and stock returns. Nominal zero-coupon yields are taken from the updated database of Gürkaynak, Sack, and Wright (2007) and we focus on the 3-month, 10-year and 30-year maturities. Real yields are from Gürkaynak, Sack, and Wright (2010)'s updated database and we focus on the following zero-coupon yield maturities: 2 years and 10 years. The real short-term rate is defined as the 3-month nominal rate minus a corresponding inflation expectation taken from the Survey of Professional Forecasters (Federal Reserve Bank of Philadelphia). Series pertaining to stocks are from the updated Shiller (2015)'s database.

\subsection{Taking the model to the data}

The parameters of the model are set in three steps. First, some parameters are calibrated based on the literature. Following Campbell and Cochrane (1999) and Wachter (2006), we set the utility curvature parameter $\gamma$ to 2. Moreover, the "leverage parameter" $\rho_{d}$, that is the semi-elasticity of the dividend growth rate to consumption growth (see Eq. 19), is set to 2. This value is in between the unit elasticity considered by Campbell and Cochrane (1999) or Wachter (2005) and the estimates obtained by Abel (1999), Collin-Dufresne, Johannes, and Lochstoer (2016) and Seo and Wachter (2018) - of 2.74, 2.5 and 2.6, respectively.

Second, we specify the distribution of the consumption innovation ( $v_{t}$, Eq. 10). To allow for non-zero skewness and excess kurtosis, we assume that $v_{t}$ is drawn from a mixture of Gaussian distributions: $\mathcal{N}\left(\eta p, \sigma_{v}^{2}\right)$ with probability $1-p$ and $\mathcal{N}\left(-\eta(1-p), \sigma_{v}^{2}\right)$ with probability $p$. If $p$ is low and $\eta$ is positive, the situation in which $v_{t}$ is drawn from $\mathcal{N}\left(-\eta, \sigma_{v}^{2}\right)$ can be interpreted as a recession. Hence, $p$ can be seen as a recession probability and $\eta$ as the recession-induced consumption drop. Overall, the distribution of $v_{t}$ depends on three parameters $\left(p, \eta\right.$ and $\left.\sigma_{v}^{2}\right)$, which are set so as to perfectly capture the variance, skewness and kurtosis of the year-on-year consumption growth. The resulting distributional fit is illustrated in Figure 2.

Third, the remaining parameters are set to match selected sample moments. Specifically, we consider first- and second-order moments pertaining to inflation and real GDP growth, as well as nominal and real bond yields. Furthermore, we exploit the similarities between stocks (for which data exist) and GDP-linked bonds (for which data do not exist) by also targeting stock-related moments. Targeted 
FIGURE 2. Data and model-implied distributions of the consumption shock $\left(v_{t}\right)$

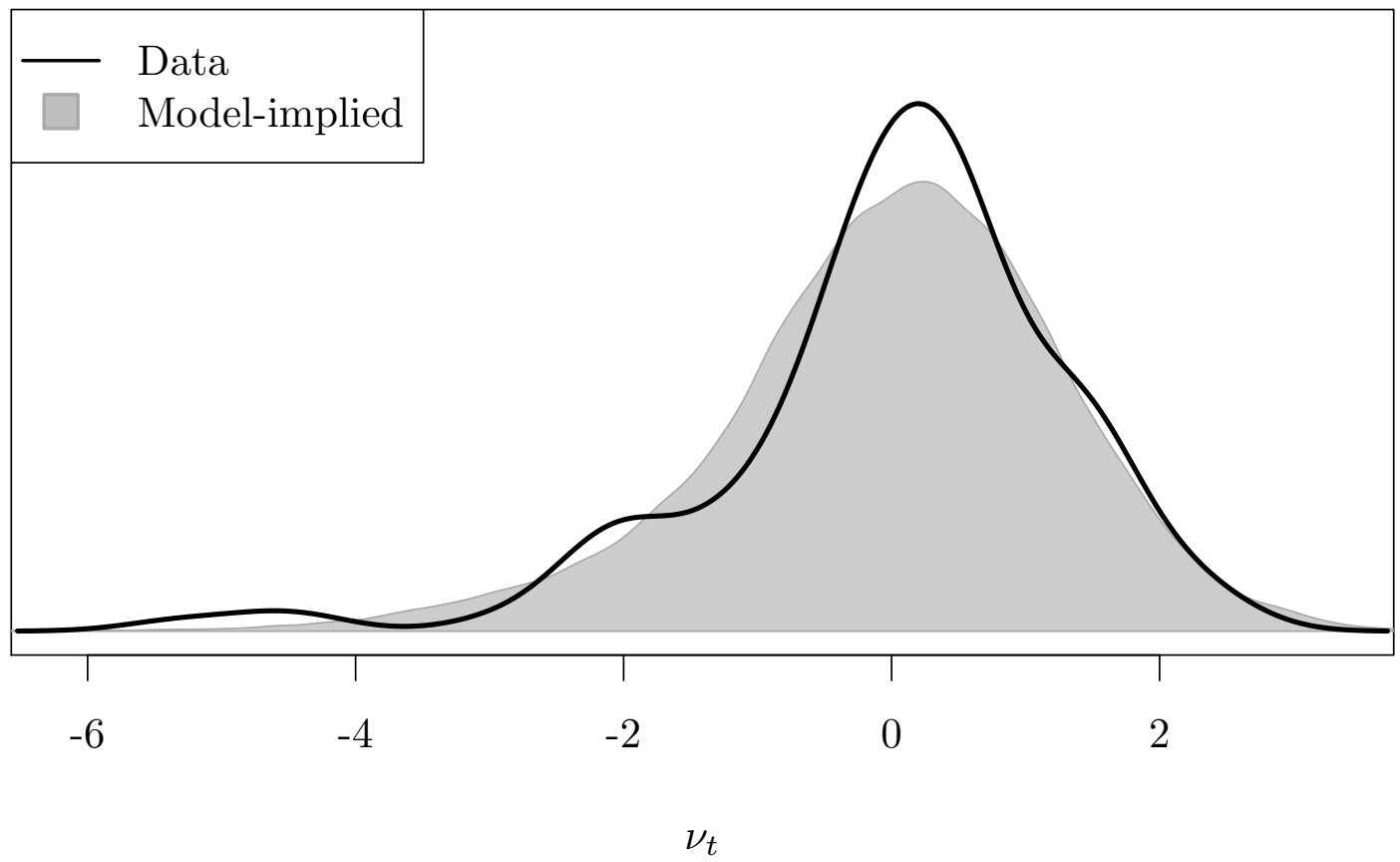

Note: This figure compares the kernel-based estimate of the distribution of the (demeaned) year-on-year consumption growth rate and its model-counterpart. $v_{t}$ is assumed to be drawn from a mixture of Gaussian distribution. Specifically, $v_{t}=B_{t} W_{1, t}+$ $\left(1-B_{t}\right) W_{2, t}$, where $B_{t} \sim \mathcal{B}(p), W_{1, t} \sim \mathcal{N}\left(-\eta(1-p), \sigma_{v}^{2}\right)$ and $W_{2, t} \sim \mathcal{N}\left(\eta p, \sigma_{v}^{2}\right)$. Equivalently, in Eq. (10), we have $v_{t}=$ $-\left(B_{t}-p\right) \eta+\varepsilon_{t}^{v}, \quad \varepsilon_{t}^{v}=$ i.i.d. $\mathcal{N}\left(0, \sigma_{v}^{2}\right)$. The three parameters $\left(p, \sigma_{v}\right.$ and $\left.\eta\right)$ are set so as to match the second-, third- and fourth-order moments of $\log \left(C_{t} / C_{t-4}\right)$, see Subsection 3.4.

moments are detailed in the first column of Table $2 .{ }^{14}$ Note that we do not only consider unconditional means and variances: for stock returns and zero-coupon yields, we also consider the model's ability to replicate (average) conditional volatilities. ${ }^{15}$

Let us denote by $\theta$ the vector of parameters to be estimated (excluding $\gamma, \rho_{d}, p, \eta$ and $\sigma_{v}^{2}$ ), and let $\mathcal{M}_{\text {Target }}$ and $\mathcal{M}(\theta)$ be the vectors of targeted moments and model-implied moments, respectively. The parameter values $\hat{\theta}$ are obtained by minimizing the distance between $\mathcal{M}(\theta)$ and $\mathcal{M}_{\text {Target }}$ :

$$
\hat{\theta}=\underset{\theta}{\operatorname{argmin}}\left(\mathcal{M}(\theta)-\mathcal{M}_{\text {Target }}\right)^{\prime} \Omega\left(\mathcal{M}(\theta)-\mathcal{M}_{\text {Target }}\right),
$$

where $\Omega$ is a diagonal matrix whose non-zero entries are weights that are arbitrarily set in order to have a satisfying overall fit of moments.

The estimated (and calibrated) parameter values are summarized in Table 3. Moreover, the last column of Table 2 reports the model-implied first- and second-order moments. The fit is predominantly satisfactory despite the breadth of moments we account for. Consequently, the ability of our model to

\footnotetext{
${ }^{14}$ The formulas used to compute model-implied moments are detailed in Online Appendices II and III.

${ }^{15}$ Observed averages of conditional volatilities are sample averages of realized volatilities, which are based on daily data of stock returns and yields.
} 
replicate the joint dynamics of observed macroeconomic and financial variables gives us confidence in using it to assess the debt-stabilizing properties of GDP-linked bonds.

TABLE 2. Fitted moments

\begin{tabular}{|c|c|c|c|}
\hline Moment description & & Data & Model \\
\hline Mean of GDP growth rate $\Delta y_{t}$ & $\times 10^{2}$ & 0.65 & 0.55 \\
\hline Mean of consumption growth rate $\Delta c_{t}$ & $\times 10^{2}$ & 0.47 & 0.55 \\
\hline Mean of inflation $\pi_{t}$ & $\times 10^{2}$ & 0.54 & 0.70 \\
\hline Std. dev. of GDP growth rate $\Delta y_{t}$ & $\times 10^{2}$ & 0.57 & 0.65 \\
\hline Std. dev. of consumption growth rate $\Delta c_{t}$ & $\times 10^{2}$ & 0.48 & 0.65 \\
\hline Std. dev. of inflation $\pi_{t}$ & $\times 10^{2}$ & 0.24 & 0.36 \\
\hline Mean of short-term nom. rate & $\times 10^{2}$ & 2.32 & 2.83 \\
\hline Mean of 10 -year nom. rate & $\times 10^{2}$ & 5.43 & 4.09 \\
\hline Mean of 30-year nom. rate & $\times 10^{2}$ & 5.77 & 6.00 \\
\hline Std. dev. of short-term nom. rate & $\times 10^{2}$ & 2.17 & 2.14 \\
\hline Std. dev. of 10 -year nom. rate & $\times 10^{2}$ & 2.33 & 2.04 \\
\hline Std. dev. of 30-year nom. rate & $\times 10^{2}$ & 1.95 & 1.78 \\
\hline Auto-correl. of short-term nom. rate & & 0.99 & 0.98 \\
\hline Auto-correl. of 10-year nom. rate & & 0.99 & 0.98 \\
\hline Auto-correl. of 30-year nom. rate & & 0.98 & 0.98 \\
\hline Mean of slope of the nom. yd curve (3m-30yrs) & $\times 10^{2}$ & 2.45 & 3.17 \\
\hline Std. dev. of slope of the nom. yd curve (3m-30yrs) & $\times 10^{2}$ & 1.43 & 0.82 \\
\hline Mean of short-term real rate & $\times 10^{2}$ & 0.14 & 0.06 \\
\hline Mean of 2-year real rate & $\times 10^{2}$ & 0.08 & 0.43 \\
\hline Mean of 10 -year real rate & $\times 10^{2}$ & 1.67 & 1.69 \\
\hline Std. dev. of short-term real rate & $\times 10^{2}$ & 1.95 & 2.14 \\
\hline Std. dev. of 2-year real rate & $\times 10^{2}$ & 1.36 & 2.11 \\
\hline Std. dev. of 10 -year real rate & $\times 10^{2}$ & 1.29 & 2.04 \\
\hline Auto-correl. of short-term real rate & & 0.81 & 0.98 \\
\hline Auto-correl. of 2-year real rate & & 0.86 & 0.98 \\
\hline Auto-correl. of 10-year real rate & & 0.98 & 0.98 \\
\hline Mean of slope of the real yd curve (3m-10yrs) & $\times 10^{2}$ & 2.01 & 1.26 \\
\hline Std. dev. of slope of the real yd curve (3m-10yrs) & $\times 10^{2}$ & 1.25 & 0.13 \\
\hline Mean of condi. var. of the short-term nom. rate & $\times 10^{5}$ & 1.39 & 2.06 \\
\hline Mean of condi. var. of the 30 -year nom. rate & $\times 10^{5}$ & 2.22 & 1.47 \\
\hline Mean of condi. var. of the 10 -year real rate & $\times 10^{5}$ & 1.33 & 2.34 \\
\hline Average expected excess return (annualized) & $\times 10^{2}$ & 7.78 & 6.65 \\
\hline Average cond. volat. of stock return (annualized) & $\times 10^{2}$ & 15.69 & 19.92 \\
\hline Average $\mathrm{P} / \mathrm{D}$ & & 40.93 & 43.09 \\
\hline Std. dev. of P/D & & 17.32 & 14.54 \\
\hline
\end{tabular}

Note: This table reports sample moments and their model-implied counterpart. 
TABLE 3. Calibrated and estimated parameter values

\begin{tabular}{|c|c|c|c|}
\hline \multirow{2}{*}{$\begin{array}{l}\text { Rate of preference for present } \\
\text { Risk aversion parameter }\end{array}$} & \multicolumn{2}{|l|}{$\delta$} & \multirow{2}{*}{$\begin{array}{c}0.996 \\
2.0\end{array}$} \\
\hline & $\gamma$ & & \\
\hline \multirow{4}{*}{ Consumption growth (eq. 10 and Subsection 3.4) } & $g_{c}$ & $\times 10^{2}$ & 0.550 \\
\hline & $\sigma_{\varepsilon}$ & $\times 10^{3}$ & 5.420 \\
\hline & $p$ & $\times 10^{2}$ & 2.117 \\
\hline & $\eta$ & $\times 10^{2}$ & 2.496 \\
\hline \multirow{2}{*}{ GDP growth shocks (eq. 11) } & $\rho_{y}$ & & 1.000 \\
\hline & $\sigma_{y}$ & $\times 10^{3}$ & 0.015 \\
\hline \multirow{4}{*}{ Inflation dynamics (eq. 12) } & $\bar{\pi}$ & $\times 10^{2}$ & 0.697 \\
\hline & $\psi$ & & 0.981 \\
\hline & $\rho_{\pi}$ & & 0.039 \\
\hline & $\sigma_{\pi}$ & $\times 10^{3}$ & 0.661 \\
\hline \multirow{2}{*}{ Dynamics of consumption ratio (eqs. 16,17 and 18) } & $\phi$ & & 0.977 \\
\hline & $b$ & $\times 10^{2}$ & 2.016 \\
\hline \multirow{3}{*}{ Growth rate of dividends (eq. 19) } & $\overline{\overline{d i v}}$ & $\times 10^{2}$ & 0.550 \\
\hline & $\rho_{d}$ & & 2.000 \\
\hline & $\sigma_{d}$ & $\times 10^{3}$ & 0.031 \\
\hline
\end{tabular}

\section{RESULTS}

In this section, we use the estimated model of Subsection 3.4 and present the resulting term structure of GDP-linked bonds. Moreover, we simulate debt-to-GDP ratios resulting from different public debt strategies involving nominal, inflation-linked and GDP-linked bonds, and investigate their respective cost and risk implications.

\subsection{The term structure of GDP-linked bond yields}

We first build the model-implied average term structures of interest rates of nominal, inflation-linked and GDP-linked bonds, for maturities up to 50 years, which are displayed on Figure 3. The dotted line depicts average nominal rates $\left(i_{t, h}\right.$, Eq. 1$)$ across maturities, while the gray and black solid lines represent average inflation-linked and GDP-linked bond rates ( $r_{t, h}$ and $r_{t, h}^{*}$, Eqs. 2 and 4$)$, respectively. The white and gray dots represent sample averages of nominal and real yields, respectively. All three average yield curves are upward sloping. This is in line with empirical evidence, as shown by the fit of the average nominal and real (inflation-linked) yield curves. As discussed in Subsection 2.1, $r_{t, h}$ and $r_{t, h}^{*}$ coincide when there is no uncertainty about real GDP. As a consequence, the wedge between the two solid lines represents the additional compensation (known as the risk premium) required by investors to hold GDP-linked bonds. This GDP risk premium amounts to 40 basis points at short- to mediumterm maturities and 30 basis points at long-term maturities. Our estimates are at the bottom of the range of available values found in the literature, as shown in Table 4. 
FIGURE 3. Term structures of interest rates

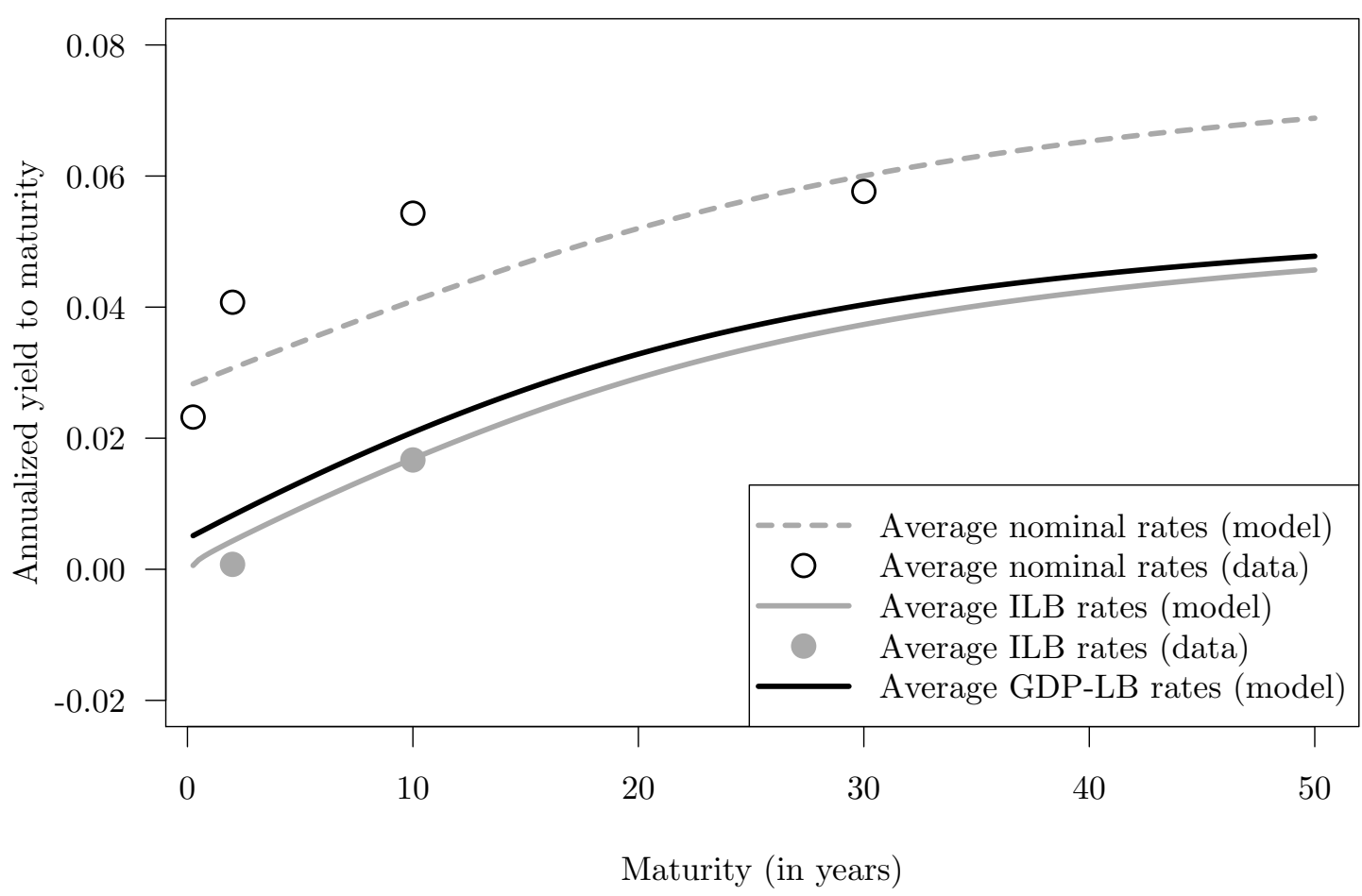

Note: This figure displays model-implied yield curves. Nominal, real, and GDP-linked bond yields-to-maturity are respectively defined by Eqs. (1), (2) and (4); the corresponding pricing formulas are Eqs. (a.6), (a.6) and (a.7) of Appendix B. Dots represent sample averages of nominal and real yields. Yields are annualized.

TABLE 4. Characteristics of zero-coupon debt instruments

\begin{tabular}{|c|c|c|}
\hline & R.P. & Approach \\
\hline Eguren-Martin, Meldrum, and Yan (2020) & $0-400 \mathrm{bps}$ & Replication of dividend swaps \\
\hline Kamstra and Shiller (2009) & 150 bps & CAPM \\
\hline Borensztein and Mauro (2004) & 40 bps & CAPM \\
\hline Barr, Bush, and Pienkowski (2014) & 35 bps & CCAPM \\
\hline Blanchard, Mauro, and Acalin (2016) & $100 \mathrm{bps}$ & - \\
\hline Pisani-Ferry, Vihriälä, and Wolff (2013) & $150 \mathrm{bps}$ & - \\
\hline Fratzscher, Große-Steffen, and Rieth (2014) & $0 \mathrm{bp}$ & Risk-neutral investors \\
\hline Chamon and Mauro (2006) & $0 \mathrm{bp}$ & Risk-neutral investors \\
\hline \multicolumn{3}{|c|}{$\begin{array}{l}\text { Note: This table reports the values of GDP-linked bond premiums estimated or used in other studies. Eguren-Martin, Meldrum, and Yan } \\
\text { (2020) estimate a no-arbitrage affine term structure model of dividend swaps and use it to price hypothetical bonds with cash-flows indexed } \\
\text { to the level of US GDP - exploiting the correlation between GDP surprises and stock returns (illustrated by Figure 1). CAPM refers to the } \\
\text { Capital Asset Pricing Model (CAPM) where premiums rely on the } \beta \text { s estimated on stock return data. CCAPM refers to the Consumption- } \\
\text { based CAPM. Blanchard, Mauro, and Acalin (2016) and Pisani-Ferry, Vihriälä, and Wolff (2013) explicitly state that their risk premium } \\
\text { assumptions are arbitrary. }\end{array}$} \\
\hline
\end{tabular}

Looking at the model-implied probability density functions (p.d.f.) of inflation-linked and GDP-LB yields offers additional insights. As illustrated in Figure 4, the model-implied distributions of both inflation- and GDP-linked yields at a 2-year (left plot) and 10-year (right plot) maturity are positively skewed. Moreover, in line with Figure 3, the distributions of GDP-LB yields are shifted to the right 
by the average GDP risk premium (about 40 basis points), in comparison with the distributions of real yields.

FIGURE 4. Model-implied distributions of real and GDP-linked bond yields

Maturity: 2 years

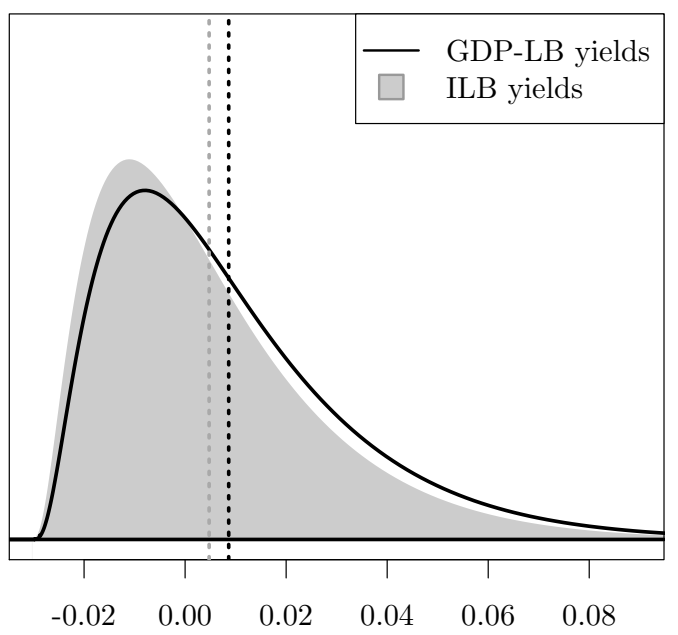

Annualized yield to maturity
Maturity: 10 years

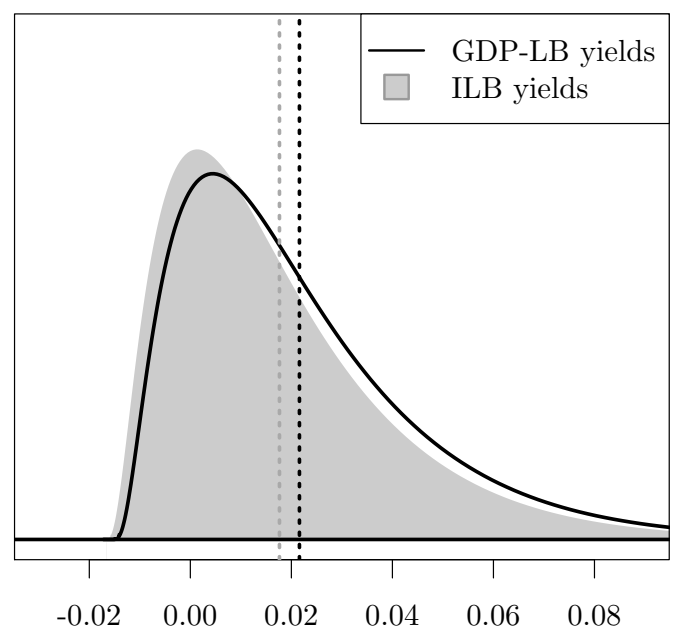

Annualized yield to maturity

Note: This figure displays the model-implied distributions of real (ILB) and GDP-linked bond (zero-coupon) yields. Vertical bars indicate means. Yields are annualized.

As shown in Wachter (2006), in our framework, the risk premium is time-varying and countercyclical. More precisely, it appears to be higher in bad states of the economy (i.e., when the consumption surplus is low) than in good states (i.e., when the consumption surplus is high). Indeed, Figure 5 indicates that, following a negative shock, the consumption surplus shrinks towards zero as average consumption $\widetilde{C}_{t}$ gets closer to habit $X_{t}$. Such a situation is associated with high real and GDP-linked-bond yields, represented by gray and black solid lines, respectively. Importantly, GDP-linked yields are higher than real yields at any level of consumption surplus and for all maturities. Therefore, given the inverse relationship between bond prices and yields, it would require a larger issuance of GDP-LBs, relative to inflation-linked bonds, to raise a particular amount. In other words, issuing GDP-LBs is on average more costly than issuing inflation-linked bonds.

These findings suggest that treasuries may be prompted to issue GDP-LBs during expansions. However, the treasury - that issues government bonds- complies with principles that preclude such opportunistic issuances, in other words issuing debt in a regular and predictable manner. Not complying would have negative repercussions on the liquidity of the sovereign marketable debt, ultimately affecting its price (Bank for International Settlements, 1999; Favero, Missale, and Piga, 2000; Mylonas et al., 2000; OECD, 2018). Accordingly, in our simulation exercises, we preclude active management strategies and only focus on passive ones. 
FIGURE 5. Yields and consumption surplus

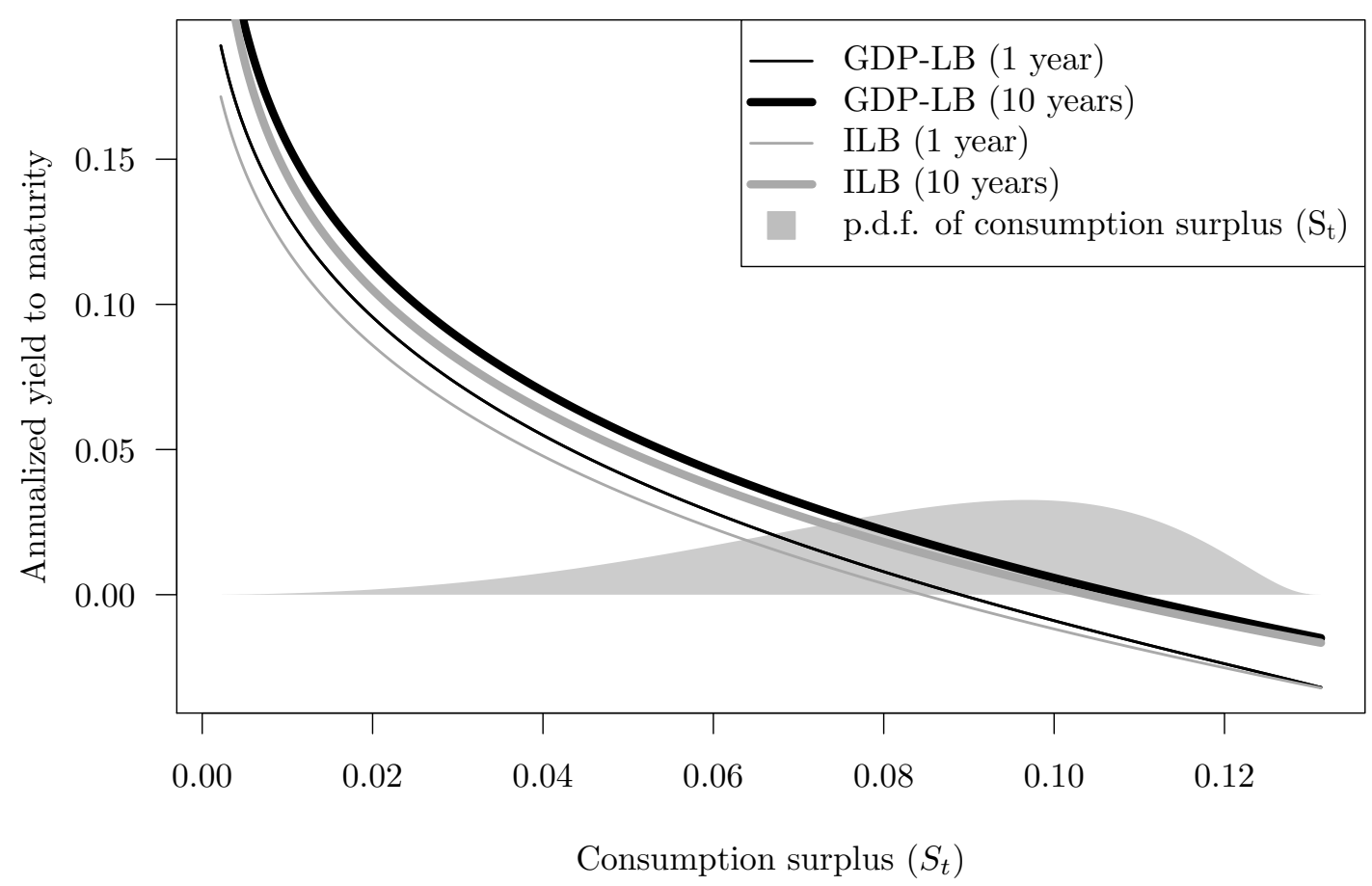

Note: This figure shows the relationship between real (ILB) and GDP-linked bond yields and the surplus of consumption. The gray area is the probability distribution function (p.d.f.) of the surplus of consumption $S_{t}$, as defined in Eq. (14). Yields are annualized.

\subsection{The debt-stabilizing properties of GDP-linked bonds}

In the previous subsection, we established that, on average, GDP-linked bonds command higher yields to maturity than their inflation-linked bond counterparts, and that this wedge reflects a positive and time-varying risk premium. Although indexing debt to GDP seems to be more costly on average, we now examine whether this additional cost has the benefit of superior debt-stabilizing properties.

To this end, we run Monte-Carlo simulations using the approach depicted in Figure 6. Specifically, we first draw $v_{t}, \varepsilon_{t}^{y}$ and $\varepsilon_{t}^{\pi}$ shocks from their respective estimated distributions (see Subsection 3.4). ${ }^{16}$ This provides us with the simulated paths of: (i) macroeconomic variables (using Eqs. 10, 11, 12, 16 and 17) and (ii) bond yields (using Eqs. a.5, a.6 and a.7). In a second step, we implement a specific issuance strategy in order to obtain the debt trajectory. More formally, a debt strategy is a function that associates the issued amounts $\left\{i s s_{t, h^{\prime}}^{n} i s s_{t, h}^{r}, i s s_{t, h}^{*}\right\}_{h=1, \ldots, H}$ with the observed current state of the economy.

\footnotetext{
${ }^{16}$ Intead of directly drawing from the distribution of the shocks $v_{t}$, we simulate the trajectory of the discretized values of $s_{t}$, which indirectly depends on $v_{t}$. Specifically, the discretized values of $s_{t}$ are defined through the selection vector $z_{t}$, such that $s_{t} \approx s_{z, t}=\mu^{\prime} z_{t}$ (see Appendix A.1). Moreover, the dynamics of the (discretized) state variable $z_{t}$ is entirely defined by its matrix of transition probabilities that is made explicit in Appendix A.1 (Eq.a.1). The transition probabilities are based on Eq. (16) and consequently on the distribution of $v_{t}$. In our simulations, we therefore retrieve the simulated values of $v_{t}$ by inverting Eq. (16) - hence, by replacing the $s_{t}$ 's by $s_{z, t}$ 's. Note that the $z_{t}$ 's are particularly useful because they determine the values of the simulated yields, as shown in Eqs. (a.5), (a.6) and (a.7).
} 
As mentioned earlier, we focus on simple "constant" strategies whereby the government issues a single type of bonds (either nominal, inflation-linked or GDP-linked) with maturities comprised between 1 and $H$ quarters, with the issuance proceeds being evenly spread across maturities. For instance, in one of the strategies we consider, the government issues GDP-linked bonds with maturities of 3 months, 6 months, ..., 10 years, that is: $i s s_{t, h}^{n}=i s s_{t, h}^{r}=0$ for all maturities $h$, and $i s s_{t, h}^{*}=I_{t} /\left(Y_{t} P_{t}\right)$ if $h \leq 40$ (quarters), and 0 otherwise.

FIGURE 6. Schematic representation of our approach

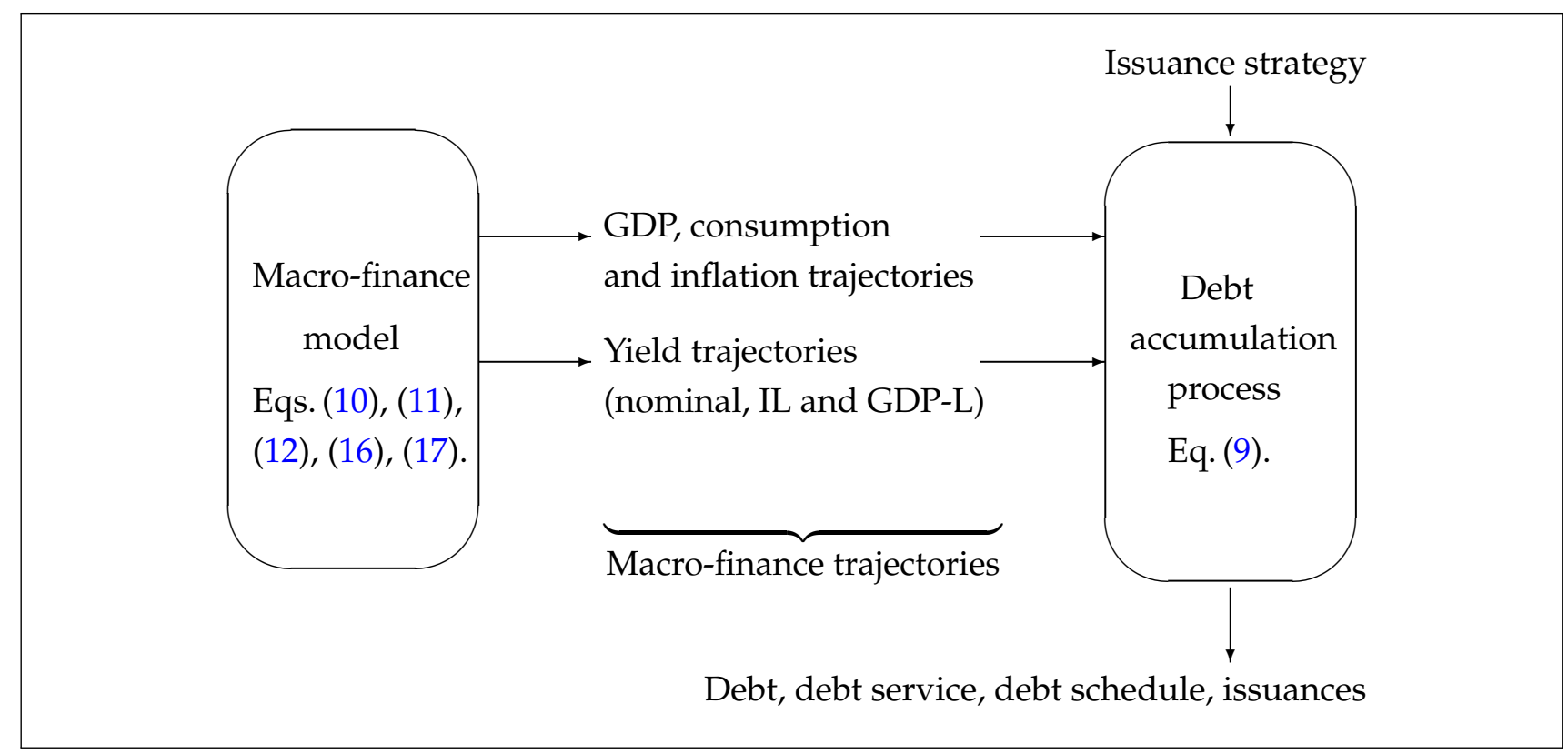

We consider two extreme situations regarding the fiscal reaction function. To this end, we conduct two exercises that differ in the way the primary budget surplus is determined. In the first exercise, the fiscal authority does not react to the debt-to-GDP ratio, and the primary budget surplus is set to a constant value. For a given issuance strategy and model-implied economic path, the dynamics of the debt-to-GDP ratio is determined by Eq. (9). In the second one, the fiscal authority aims at perfectly stabilizing the debt-to-GDP ratio. This strategy consists in setting the primary budget surplus to its debt-stabilizing value (previously defined as DSBS in Subsection 2.3).

Although none of these two exercises should be seen as realistic, an issuance strategy that achieves either a constant debt-to-GDP ratio (first exercise) or a DSBS (second exercise) is consistent with the notion of fiscal insurance developed in the optimal public debt management literature (Faraglia, Marcet, and Scott, 2008, 2010). Indeed, all else being equal, such strategies reduce the need for aggressive fiscal adjustments to ensure the government's intertemporal solvency. ${ }^{17}$

\footnotetext{
${ }^{17}$ Empirical studies suggest that primary budget balances positively react to debt-to-GDP ratios (see e.g. Bohn, 1998; Mendoza and Ostry, 2008; Ghosh, Ostry, and Qureshi, 2013). However, the data also suggest that the adjustment weakens for
} 
4.2.1. Simulations under a constant budget-surplus. In the first exercise, we compare different issuance strategies by simulating model-implied paths for macroeconomic variables and bond yields over a twenty-year period. In the context of this exercise, budget surpluses are set at a constant fraction of GDP (equal to $-1 \%$ ) and the initial level of debt is set at $100 \%$ of GDP. The resulting debt-to-GDP paths are obtained from Eq. (9). ${ }^{18}$

Figure 7 displays the simulated debt-to-GDP paths associated with different issuance strategies: nominal, inflation-linked or GDP-linked bonds. Each column represents a given simulation and each row corresponds to the issuance of short-term (1 to 4 quarters) and long-term bonds (1 to 40 quarters), respectively. The random simulations in Figure 7 suggest that (a) the debt-to-GDP trajectories are smoother when GDP-LBs are issued, however $(b)$ the issuance of GDP-LBs is not necessarily more beneficial in taming debt-to-GDP paths: on several occasions, the debt-to-GDP paths are higher under GDP-linked bond issuances. Result (a) implies that the high-frequency movements in debt-to-GDP are filtered out when issuing GDP-LBs, suggesting that the debt-to-GDP ratio is easier to predict. Notably, the smoothing effect is stronger when long-term bonds are issued as a lower share of debt has to be refinanced in each period. This result generalizes findings in most studies on GDP-LBs, since the latter only focus on short-term issuances. However, because the issuance price of GDP-linked bonds randomly fluctuates over time, medium- to low-frequency fluctuations in the debt-to-GDP ratio are not eliminated by the issuance of GDP-LBs. Let us stress that such an effect can only be detected in a modeling environment that accounts for time-varying bond prices because their fluctuations are the only stochastic driver of the debt-to-GDP ratio in an environment of constant budget surpluses. To the best of our knowledge, none of the existing literature performing Monte-Carlo simulations to study the smoothing properties of GDP-LBs allows for time-varying bond prices (or yields-to-maturity), thereby mechanically overestimating the stabilization property of these bonds.

Naturally, a large number of simulated trajectories is necessary to draw conclusions regarding the influence of issuance strategies on the distribution of the debt-to-GDP ratio at a given horizon. We simulate 10.000 macro-finance trajectories covering a 20-year period and employ kernel approaches to approximate the distributions of the debt-to-GDP ratios at different horizons.

Figure 8 depicts such distributions in a setup where the government only issues one type of zerocoupon bonds - either nominal, inflation-linked or GDP-linked - with maximum maturities of 1 and 10 years. We evaluate these distributions after 2 years (left-hand side charts) and 20 years (right-hand side charts) of the government following these strategies. Each row represents the issuance of bonds of a

large debt-to-GDP ratios. The latter phenomenon, dubbed as "fiscal fatigue" implies the existence of fiscal limits (see Ghosh et al., 2013).

${ }^{18}$ It is assumed that the initial outstanding debt results from issuances that are evenly distributed over the period preceding the start of our simulation. Therefore, while the initial debt-to-GDP ratios are the same across simulations and issuance strategies, the initial debt repayment schedules are not the same. One could however imagine that all simulations start form the same situation, if interest-rate derivatives -namely interest-rate swaps, inflation-linked swaps and (hypothetical) GDPlinked swaps- are employed to obtain the desired debt structure. 


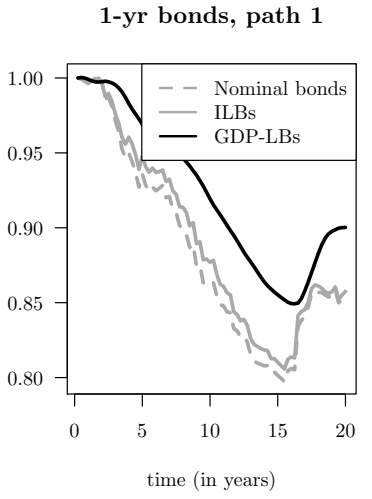

10-yr bonds, path 1

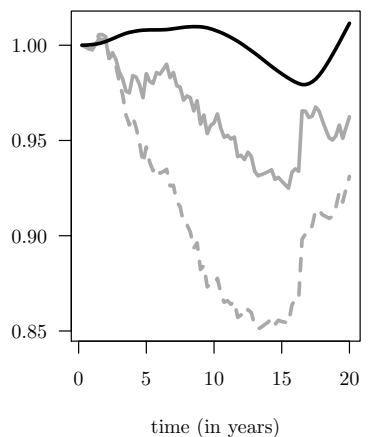

1-yr bonds, path 2

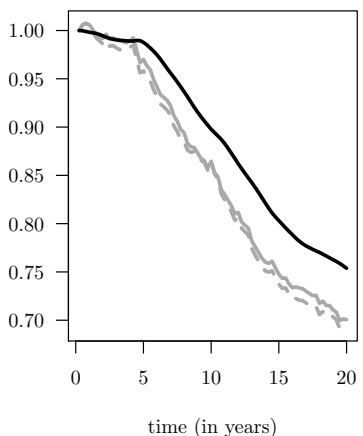

10-yr bonds, path 2

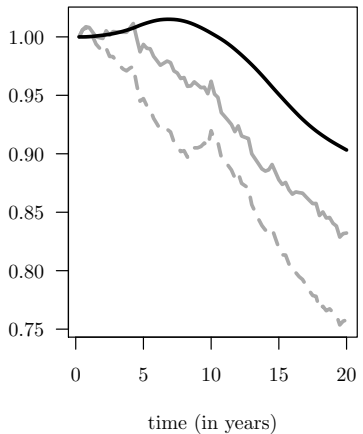

1-yr bonds, path 3

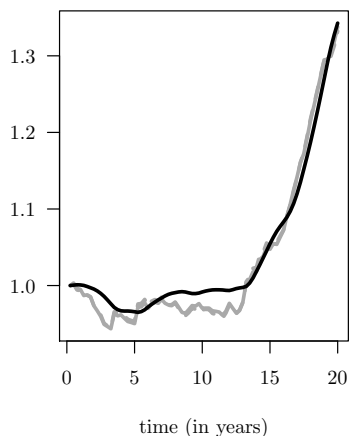

10-yr bonds, path 3

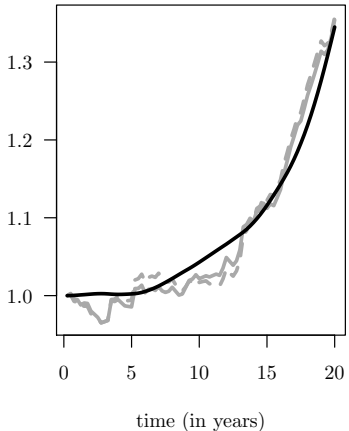

1-yr bonds, path 4

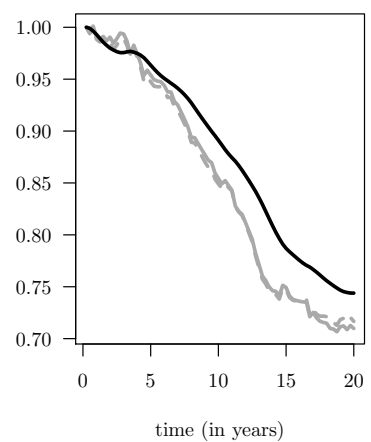

10-yr bonds, path 4

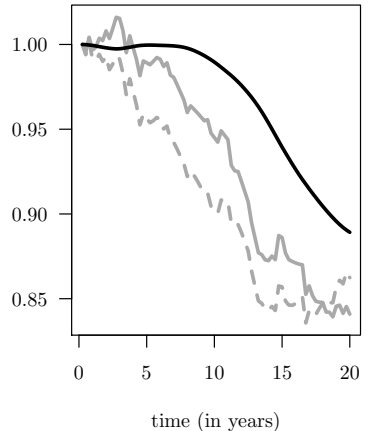

Note: This figure displays, for the sake of illustration, a small number of simulated debt paths associated with different issuance strategies. Each column of plots is based on the same simulated macro-finance sample. On each plot, we consider three situations: (i) the government issues nominal bonds only (dashed gray line), (ii) the government issues inflation-linked bonds only (gray solid lines) and (iii) the government issues GDP-linked bonds only (black solid line). The primary budget surplus is equal to $-1 \%$ of nominal GDP.

given maturity (1-year bonds with maturities ranging between 1 to 4 quarters on the first row; 10-year bonds with maturities ranging between 1 to 40 quarters on the second row) and each column is associated with a horizon over which the strategy is studied. We observe that, given the existence of strictly positive risk premiums associated with GDP-LBs, debt-to-GDP ratios are, on average, higher when the government issues GDP-LBs relative to the issuance of the two other bonds. In line with the smoothing results observed in the previous figure, the variance of the distribution of debt-to-GDP ratios at a horizon of 2 years is far lower when GDP-LBs are issued. This increased predictability is particularly clear when long-term bonds are issued (bottom left plot) because, in this context, a relatively smaller fraction of the debt has to be rolled over during the two-year period. However, at a 20-year horizon, the distributions of debt-to-GDP ratios resulting from the issuance of GDP-LBs are almost as dispersed as when conventional bonds are issued. Moreover, the distributions of debt-to-GDP ratios are shifted to the right in the case of GDP-LBs issuances, due to higher average funding costs. 
FIGURE 8. Distribution of future debt-to-GDP ratios

Maturity of bonds: 1 year, Horizon: 2 years

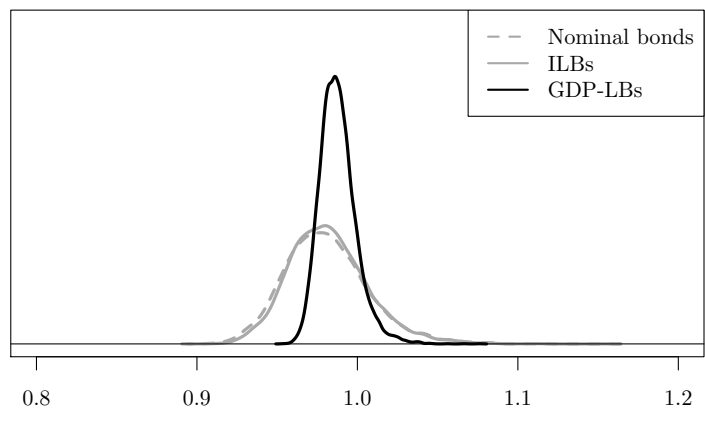

Debt-to-GDP ratio

Maturity of bonds: 10 years, Horizon: 2 years

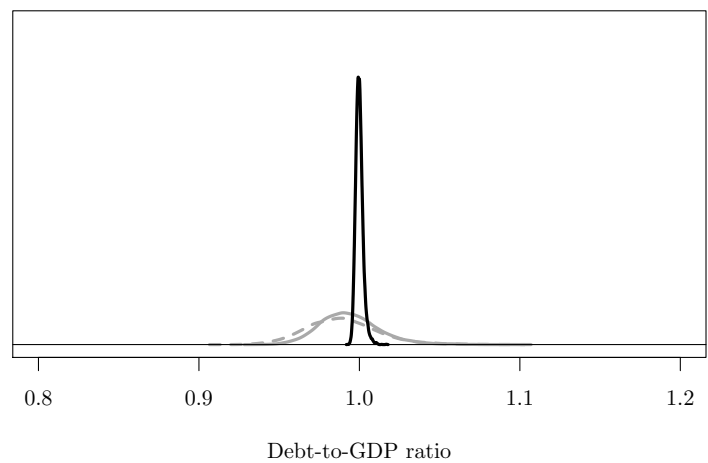

Maturity of bonds: 1 year, Horizon: 20 years

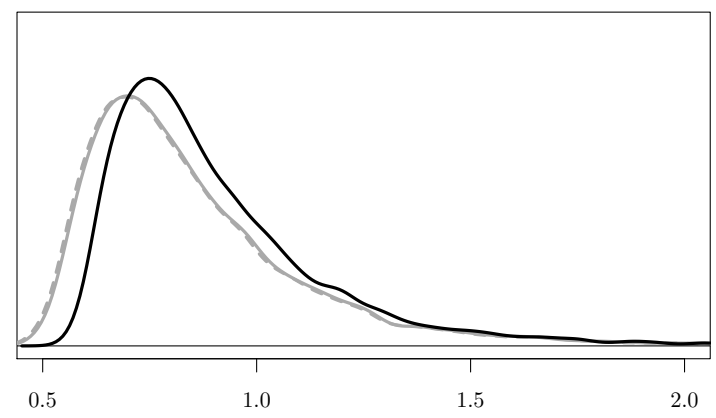

Debt-to-GDP ratio

Maturity of bonds: 10 years, Horizon: 20 years

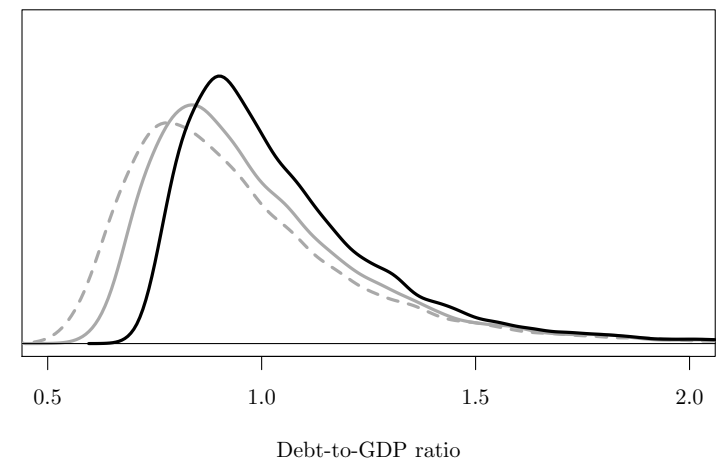

Note: This figure displays the distributions of debt-to-GDP ratios after periods of 2 years (left column of plots) and 20 years (right column of plots) during which the government implements basic issuance strategies: specifically, the government issues bonds of the same type (nominal, inflation-linked or GDP-linked) and of the same maximum maturity (1 or 10 years). See the caption of Figure 7 for more details about the simulations. We simulate 10.000 macro-finance trajectories over a period of 80 quarters.

The debt-to-GDP ratio is less volatile when issuing GDP-LBs because the debt service (i.e., the increase in debt, absent of budget surpluses) resulting from these bonds is pro-cyclical. ${ }^{19}$ In other words, having a smooth debt-to-GDP ratio comes at the cost of a volatile debt service. This is illustrated in Figure 9, which displays the simulated distributions of the debt services. The distributions of future debt service are evidently flatter under GDP-linked bond issuances, thus indicating more dispersed interest payments. Moreover, due to positive risk premiums associated with GDP-LBs, interest payments under this issuance strategy also tend to be higher. Therefore, the servicing of debt is on average more expensive and more volatile when GDP-linked bonds are issued.

To get a better grasp of whether the issuance of GDP-LBs prevents high debt-to-GDP ratios, we look at high quantiles of the distribution of debt-to-GDP ratios. Table 5 reports the 50th, 90th and 95th quantiles of the debt-to-GDP ratio over a 2-year and 20-year horizon. The last lines of each panel indicate that, at a 2-year (resp. 20-year) horizon, the lowest (resp. highest) debt-to-GDP ratio is obtained

\footnotetext{
${ }^{19}$ Formally, the dynamics of the debt-service-to-GDP ratio is given by Eq. (9).
} 
FIGURE 9. Distribution of future debt service

Maturity of bonds: 1 year, Horizon: 2 years

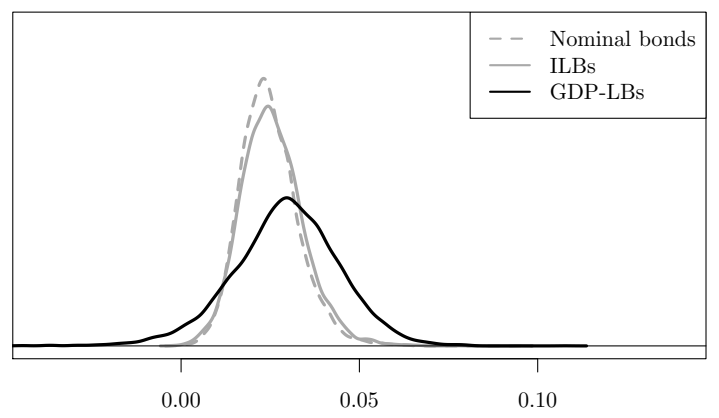

Debt service (as a fraction of GDP)

Maturity of bonds: 10 years, Horizon: 2 years

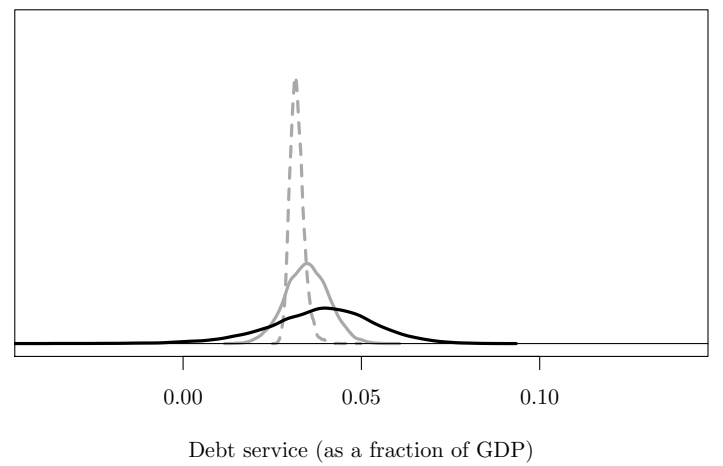

Maturity of bonds: 1 year, Horizon: 20 years

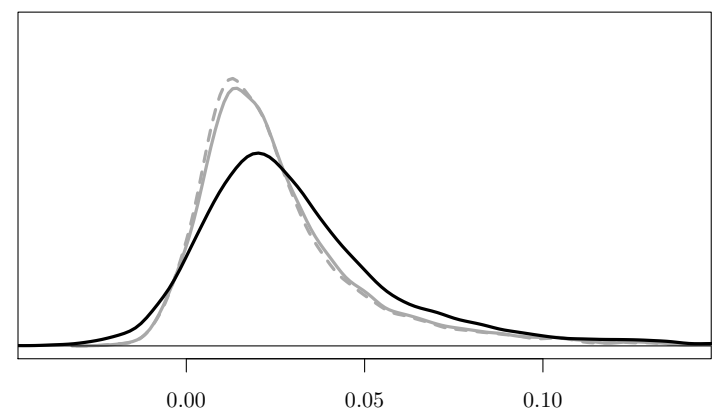

Debt service (as a fraction of GDP)

Maturity of bonds: 10 years, Horizon: 20 years

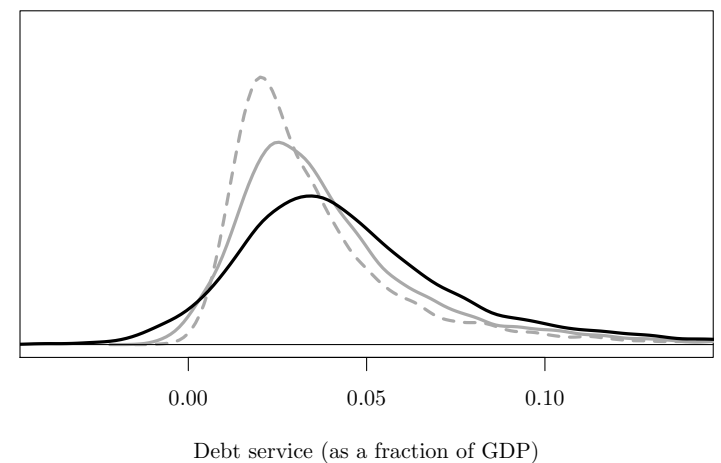

Note: This figure displays the distributions of debt service after periods of 2 years (left column of plots) and 20 years (right column of plots) during which the government implements basic issuance strategies: specifically, the government issues bonds of the same type (nominal, inflation-linked or GDP-linked) and of the same maximum maturity (1 or 10 years). See the caption of Figure 7 for more details about the simulations. We simulate 10.000 macro-finance trajectories over a period of 80 quarters.

under the issuance of GDP-LBs. Therefore, it seems that issuing GDP-LBs can tame debt-to-GDP ratios only at short horizons.

4.2.2. Simulations with debt-stabilizing budget surpluses (DSBS). In this second exercise, we study the moments of the debt-stabilizing budget surplus pertaining to different issuance strategies. Recall that the DSBS is the budget surplus the government needs to deliver in order to keep the debt-to-GDP ratio constant over time, which is obtained by setting $d_{t}-d_{t-1}=0$ in Eq. (9). We simulate a very long sample (covering 10.000 years) of DSBS and approximate the population moments using its samplebased counterparts. Debt-stabilizing budget surpluses are stationary processes when expressed as a fraction of GDP.

Figure 10 displays several cost/risk performances associated with different issuance strategies. Each issuance strategy is represented by a circle whose coordinates are: cost measures on the $x$ axis and risk measures on the $y$ axis. The average DSBS is the only cost measure we consider, as it represents the average funding cost. We consider four different risk measures: the standard deviation of the DSBS, 
TABLE 5. Influence of issuance strategies on debt-to-GDP quantiles

Panel A - Maturity of issued bonds: 1 year

\begin{tabular}{llccccc}
\hline Quantile & \multicolumn{3}{c}{ Horizon: 2 years } & \multicolumn{3}{c}{ Horizon: 20 years } \\
\hline & Nominal & Infl.-linked & GDP-linked & Nominal & Infl.-linked & GDP-linked \\
\hline $50 \%$ & 0.98 & 0.98 & 0.99 & 0.79 & 0.79 & 0.84 \\
$90 \%$ & 1.01 & 1.01 & 1.00 & 1.20 & 1.21 & 1.24 \\
$95 \%$ & 1.03 & 1.03 & 1.01 & 1.40 & 1.41 & 1.44 \\
\hline
\end{tabular}

Panel B - Maturity of issued bonds: 10 years

\begin{tabular}{llccccc}
\hline Quantile & \multicolumn{3}{c}{ Horizon: 2 years } & \multicolumn{3}{c}{ Horizon: 20 years } \\
\hline & Nominal & Infl.-linked & GDP-linked & Nominal & Infl.-linked & GDP-linked \\
\hline $50 \%$ & 0.99 & 0.99 & 1.00 & 0.89 & 0.93 & 0.99 \\
$90 \%$ & 1.02 & 1.02 & 1.00 & 1.32 & 1.35 & 1.39 \\
$95 \%$ & 1.03 & 1.03 & 1.00 & 1.52 & 1.54 & 1.57 \\
\hline
\end{tabular}

Note: This table reports the quantiles of the distributions of debt-to-GDP ratios resulting from different issuance strategies. The issuance strategies are basic strategies whereby the government, on each period, issues the same type of bonds to meet its funding needs.

the smoothness of the DSBS (defined as the annual change in the DSBS) and, the 90th and 95th quantiles of the DSBS, which provide information about the right tails of the DSBS distribution.

At first glance, several findings arise. First, the higher the maturity, the larger the cost measure (xaxis). This holds true any issuance strategy (nominal, inflation-linked or GDP-linked), and reflects the existence of positive term premiums. $^{20}$ Second, GDP-LB strategies imply larger average funding costs, for any maturity, because there is an additional positive GDP risk premium.

Regarding risk measures, we observe that, in order to stabilize the debt-to-GDP ratio, the budget surplus has to be less volatile under GDP-LB issuances, in contrast to conventional (nominal or inflation indexed) bond issuances. This result is more striking when looking at the smoothness measure. Specifically, the annual change in DSBS is dramatically smaller when issuing GDP-LBs, as is reflected by the standard deviation of the change in the DSBS, which is four times lower under this strategy. In other words, to stabilize the debt-to-GDP ratio in the short-run (with a one-year horizon), the government would have to run budget surpluses that are far easier to predict under a GDP-LB issuance. However, the tail of the distribution of the DSBS paint a less favorable picture of GDP-linked bonds. Indeed, in a bad scenario (characterized by the need to run a high budget surplus to stabilize debt), achieving debt stabilization requires larger budget-surpluses under GDP-LB issuances. For instance, focusing on the 95th percentile, we find that budget surpluses as high as 3.3\% of GDP have to be run in $5 \%$ of the simulated periods when up-to-10-year GDP-linked bonds are issued, as opposed to $3.1 \%$ when up-to-10-year conventional bonds are issued.

\footnotetext{
${ }^{20}$ Positive term premiums graphically correspond to the positive slopes of the average yield curves shown in Figure 3.
} 
FIGURE 10. Effect of issuance strategies on DSBS risk measures

Risk measure: Std dev. of DSBS

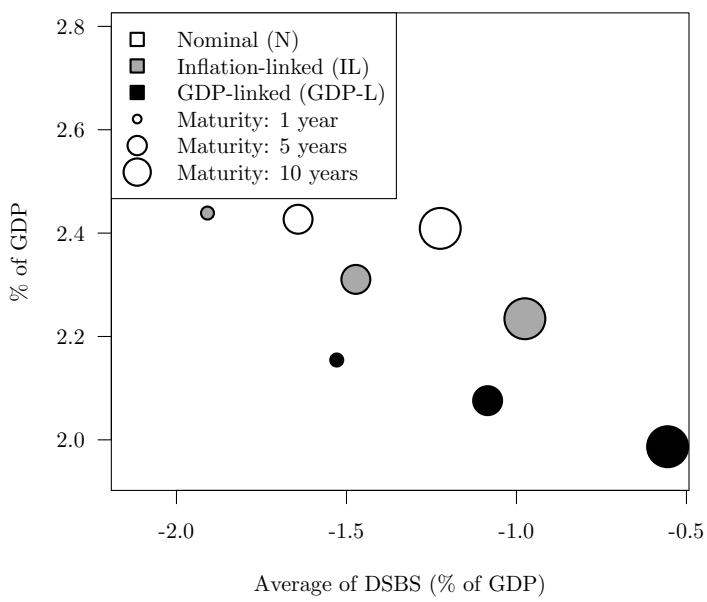

Risk measure: 90th percentile of DSBS

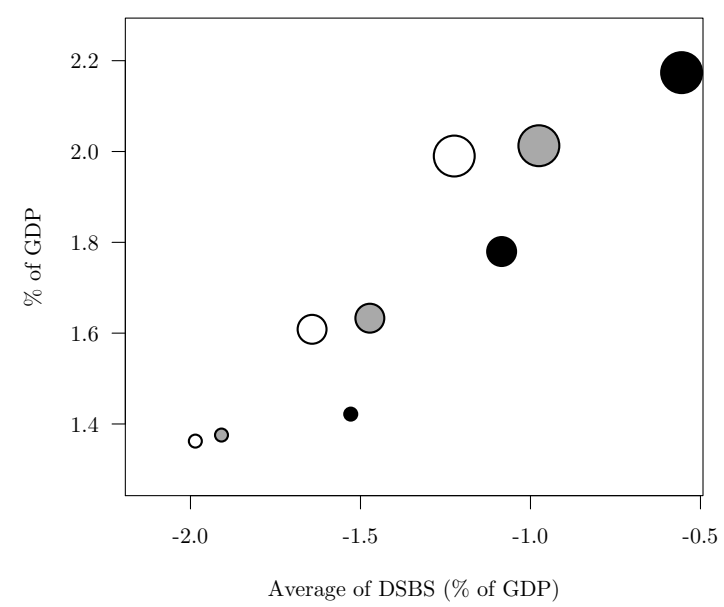

Risk measure: Std dev. of chges in DSBS

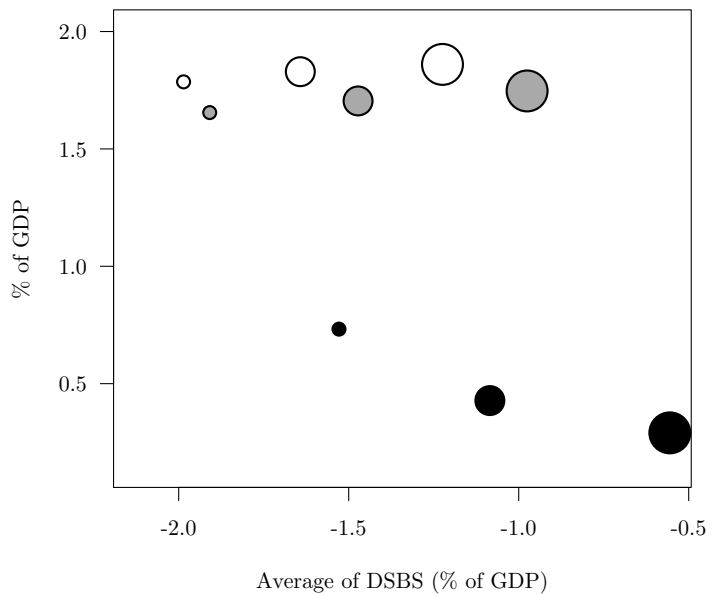

Risk measure: 95th percentile of DSBS

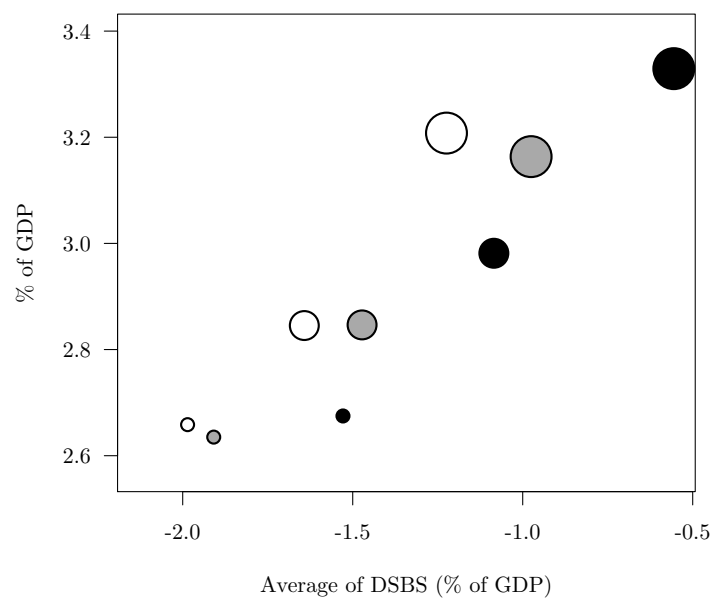

Note: This figure depicts risk measures associated with the debt-stabilizing budget surplus (DSBS) of different issuance strategies. The DSBS is the budget surplus that the government needs to deliver in order to keep the debt-to-GDP ratio constant over time. Each dot corresponds to a given issuance strategy (characterized by a type of bond issued: nominal, inflation-linked or GDP-linked) and a maturity. The four risk measures are: the standard deviation of the DSBS (top-left plot), the standard deviation of the annual change in the DSBS (top-right plot), the 90th percentile (bottom-left plot) and the 95th percentile (bottom-right plot) of the DSBS distribution. We simulate a macro-finance trajectory of 40.000 periods.

\section{DISCUSSION}

In this Section, we discuss several questions that arise when analyzing the usefulness of GDP-linked bonds. The first point hinges on an assumption underlying our model, while the remaining issues are of a more general nature.

Regarding the first point, in our model, we address the usefulness of GDP-LBs in the context of a closed-economy, where there is a single stochastic discount factor associated with a representative 
agent. However, several studies make the case for an international risk-sharing argument and suggest that GDP risk premiums could be contained if international business cycles are sufficiently desynchronized. In this case, periods of a domestic recession (where the payoffs of a bond indexed on domestic GDP are low) do not necessarily coincide with a "bad state of the world" from the foreign investor's point of view. Indeed, in such a context, the foreign investor does not require a high GDP risk premium, and therefore GDP-LBs might not generate interest payments that are higher than conventional bonds (e.g. Athanasoulis, Shiller, and Wincoop, 1999; Borensztein and Mauro, 2004). Against this backdrop, we propose a simple analysis to gauge the potential for GDP risk diversification. We consider eight large economies and compute pairwise correlations between measures of GDP surprises for two periods (1980-2018 and 2000-2018). ${ }^{21}$ We choose the most natural index for hypothetical GDP-linked bonds by using GDP data expressed in local currencies and at current prices.

Table 6 shows that the correlations between Brazil, China and India, on the one hand, and advanced western economies, on the other hand, are low over the two periods. This indicates that there is scope for diversification between these two groups of countries. By contrast, we observe strong correlations between advanced western economies, especially over the most recent period. This means that, bonds indexed to US GDP, for instance, offer moderate diversification opportunities to European investors, and vice-versa. As a result, diversification across advanced western economies is unlikely to considerably reduce GDP risk premiums embedded in GDP-linked bonds issued by these economies.

We now briefly discuss additional issues that have not been addressed in the present study. First, when new assets are launched in the market, such as hypothetical GDP-linked bonds, they tend to suffer from novelty and liquidity risk premiums. Empirical evidence suggests that investors tend to ask for premiums to hold a newly introduced asset. Indeed, this "novelty premium" can reflect potential difficulties in measuring the risks underlying the asset (e.g. due to the absence of appropriate and well-established models) or the limited liquidity of such bonds relative to conventional ones. ${ }^{22}$ In fact, this seems to be the case for inflation-linked bonds. Employing a no-arbitrage term-structure model, D'Amico, Kim, and Wei (2018) find that inflation-linked bond yields exceeded risk-free real rates by as much as 100 basis points when they were first issued in the U.S. and up to 300 basis points during the 2007-2008 financial crisis. ${ }^{23}$ This suggests that accounting for novelty and liquidity premiums would only accentuate our current results, given that they would add up to existing GDP risk premiums.

\footnotetext{
${ }^{21}$ GDP surprises are defined as the difference between realized GDP and a crude forecast based on simple GDP extrapolations. The latter are computed as the mean of the last five observed GDP growth rates, at each date.

${ }^{22}$ Using prices of Argentinian GDP-indexed warrants, Chamon, Costa, and Ricci (2008) find that the residual premium paid by these warrants over standard bonds was of a few hundred basis points, while it declined by about 600 basis points between December 2005 and July 2007.

${ }^{23}$ According to Shen (2009), Australia and New-Zealand are examples of countries that stopped issuing inflation-linked bonds partly because of low liquidity in secondary markets.
} 
TABLE 6. Correlations between 2-year-ahead GDP surprises

\begin{tabular}{|c|c|c|c|c|c|c|c|c|c|}
\hline & & & Panel (a) & 1980-201 & & & & & \\
\hline & U.S. & U.K. & Germany & France & Canada & Japan & Brazil & China & India \\
\hline U.S. & 1.00 & & & & & & & & \\
\hline U.K. & 0.63 & 1.00 & & & & & & & \\
\hline Germ. & 0.21 & 0.19 & 1.00 & & & & & & \\
\hline France & 0.52 & 0.41 & 0.22 & 1.00 & & & & & \\
\hline Canada & 0.75 & 0.66 & $-0 . .0$ & 0.60 & 1.00 & & & & \\
\hline Japan & 0.55 & 0.67 & 0.67 & 0.38 & 0.29 & 1.00 & & & \\
\hline Brazil & $-0 . .2$ & $-0 . .1$ & 0.51 & $-0 . .4$ & $-0 . .4$ & 0.15 & 1.00 & & \\
\hline China & $-0 . .1$ & $-0 . .0$ & $-0 . .1$ & $-0 . .5$ & $-0 . .1$ & $-0 . .2$ & 0.48 & 1.00 & \\
\hline India & $-0 . .0$ & 0.09 & 0.11 & $-0 . .1$ & $-0 . .1$ & $-0 . .0$ & 0.34 & 0.46 & 1.00 \\
\hline
\end{tabular}

Panel (b) - 2000-2018

\begin{tabular}{lrrrrrrrrr} 
& U.S. & U.K. & Germany & France & Canada & Japan & Brazil & China & India \\
\hline U.S. & 1.00 & & & & & & & & \\
U.K. & 0.95 & 1.00 & & & & & & & \\
Germ. & 0.66 & 0.64 & 1.00 & & & & & & \\
France & 0.82 & 0.85 & 0.81 & 1.00 & & & & & \\
Canada & 0.84 & 0.81 & 0.74 & 0.79 & 1.00 & & & \\
Japan & 0.91 & 0.92 & 0.66 & 0.72 & 0.68 & 1.00 & & & \\
Brazil & $-0 . .1$ & $-0 . .1$ & $-0 . .2$ & $-0 . .2$ & 0.14 & $-0 . .2$ & 1.00 & \\
China & 0.02 & -0.00 & 0.06 & 0.23 & 0.21 & $-0 . .2$ & 0.64 & 1.00 & \\
India & $-0 . .0$ & $-0 . .2$ & 0.01 & $-0 . .0$ & 0.07 & $-0 . .3$ & 0.52 & 0.81 & 1.00 \\
\hline
\end{tabular}

Note: This table reports correlations between 2-year-ahead GDP forecast errors. GDP data, in current local unit currency (LUC), are extracted from the World Bank database. GDP surprises are computed as the difference between realized GDP and a crude forecast based on simple GDP extrapolations (using, on each date, the mean of the last five observed GDP growth rates). Shaded cells indicate larger than $40 \%$ correlation coefficients.

Second, GDP-linked bonds may create a moral-hazard problem for governments. For instance, if governments are faced with lower interest payments during recessions, they are relatively less incentivized to foster economic growth. Similarly, GDP figures often incur large revisions, as more information becomes available, while national statistics may be subject to data manipulation, especially if interest payments depend on indices computed directly (or indirectly) by the government. However, Sandleris and Wright (2013) argue that this problem might be subdued by the fact that the amounts saved in lower interest payments are likely to be small relative to the direct economic harm associated with lower GDP.

Third, some financial stability issues may arise when issuing GDP-linked bonds. For example, if private market participants were to buy large amounts of GDP-linked bonds, this may leave them excessively exposed to business-cycle conditions (International Monetary Funds, 2017, Item 35). Moreover, substantial GDP-linked bond issuances would mechanically result in a decline in supply of "safer" conventional assets, that are essential for financial market transactions (Caballero, Farhi, and Gourinchas, 2017). Overall, these points attenuate arguments in support of governments issuing GDP-linked bonds. 


\section{CONCLUDING REMARKS}

Calling for the indexation of debt to GDP as a way of providing the government with an automatic stabilizer to its finance has become popular in policy circles. The present paper calls into question this view. Using a consumption-based macro-finance model, which includes the term structure of hypothetical GDP-linked bonds, we study their debt stabilizing properties. Three results stand out.

First, issuing GDP-linked bonds generates, on average, higher interest payments for the government. This is because such bonds provide lower payoffs in periods of economic downturn and hence investors are willing to hold them only if they provide an average excess return, called GDP risk premium. We find that the GDP risk premium approximately amounts to 40 basis points along the entire maturity spectrum. Hence, for a given path of primary surpluses, issuing GDP-linked bonds, rather than conventional ones, is on average costlier and inflates debt-to-GDP ratios.

Second, the prices of GDP-linked bonds are state contingent and therefore not perfectly predictable. This implies that a large fraction of the debt will have to be rolled over before a given (long-run) horizon, and since future issuance prices are not deterministic, the long-run debt-to-GDP ratio is partly unknown as of today. Our simulation exercises indicate that, at a horizon of 20 years, the debt-to-GDP ratio is not more predictable when GDP-linked bonds are issued, relative to conventional ones.

Third, the debt stabilizing budget surplus is more predictable under GDP-linked bond issuances at the expense of being higher on average. Moreover, in a bad state of the world, characterized by the need to run a high budget surplus to stabilize debt, achieving debt stabilization requires larger budget-surpluses under GDP-linked bond issuances. Our findings, thus, call into question the view that GDP-linked bonds tame debt. 


\section{Appendix A. MODEL DiscretizATION}

A.1. Discretized dynamics of $s_{t}$. We consider the following discretization of $s_{t}: s_{t} \approx \mu^{\prime} z_{t}$, where $z_{t}$ is a $N$-dimensional selection vector, i.e. $z_{t} \in\left\{e_{1}, \ldots, e_{N}\right\}$, where $e_{i}$ is the $i^{\text {th }}$ column vectors of the $N \times N$ identity matrix. Note that the largest entry of $\mu$ is lower than (or equal to) $s_{\max }$. Hence, vector $\mu$ contains the discretized values of $s_{t}$. We also introduce vector $\lambda$, whose $i^{t h}$ component is $\lambda_{i} \equiv \lambda\left(\mu_{i}\right)$.

The dynamics of $z_{t}$ is defined by the matrix $\Pi=\left\{p_{i, j}\right\}_{i, j \in[1, N]^{2}}$, called matrix of transition probabilities and defined by:

$$
\mathbb{P}\left(z_{t+1}=e_{j} \mid z_{t}=e_{i}\right)=p_{i, j}
$$

It is easily seen that we have $\mathbb{E}_{t}\left(z_{t+1}\right)=\Pi^{\prime} z_{t}$.

Let us explain how probabilities $p_{i, j}$ are computed. For this purpose, let's denote by $f$ the c.d.f. of $c_{t+1}-\mathbb{E}_{t}\left(c_{t+1}\right)$. Using $\mu_{0}=-\infty$ and $\mu_{N+1}=+\infty$, we impose that, for $i, j=1, \ldots, N$ :

$$
\begin{aligned}
\mathbb{P}\left(z_{t+1}=e_{j} \mid z_{t}=e_{i}\right)= & \left.\left.\mathbb{P}\left(s_{t+1} \in\right] \frac{1}{2}\left(\mu_{j-1}+\mu_{j}\right), \frac{1}{2}\left(\mu_{j}+\mu_{j+1}\right)\right] \mid s_{t}=\mu_{i}\right) \\
= & \mathbb{P}\left(s_{t+1} \leq \frac{1}{2}\left(\mu_{j}+\mu_{j+1}\right) \mid s_{t}=\mu_{i}\right)-\mathbb{P}\left(s_{t+1}<\frac{1}{2}\left(\mu_{j-1}+\mu_{j}\right) \mid s_{t}=\mu_{i}\right) \\
= & \mathbb{P}\left((1-\phi) \bar{s}+\phi \mu_{i}+\lambda_{i} X \leq \frac{1}{2}\left(\mu_{j}+\mu_{j+1}\right)\right) \\
& -\mathbb{P}\left((1-\phi) \bar{s}+\phi \mu_{i}+\lambda_{i} X<\frac{1}{2}\left(\mu_{j-1}+\mu_{j}\right)\right),
\end{aligned}
$$

where $X$ is a random variable whose cumulative distribution function (c.d.f.) is $f$. Hence, we have, for $i, j=1, \ldots, N$ :

$$
\begin{aligned}
p_{i, j}=\mathbb{P}\left(z_{t+1}=e_{j} \mid z_{t}=e_{i}\right)= & f\left(\frac{1}{\lambda_{i}}\left[\frac{1}{2}\left(\mu_{j}+\mu_{j+1}\right)-(1-\phi) \bar{s}-\phi \mu_{i}\right]\right) \\
& -f\left(\frac{1}{\lambda_{i}}\left[\frac{1}{2}\left(\mu_{j-1}+\mu_{j}\right)-(1-\phi) \bar{s}-\phi \mu_{i}\right]\right) .
\end{aligned}
$$

A.2. Specific vectorial notations. In the following, to simplify the derivation of formulas, we use the following non-standard vectorial notations:

$$
\begin{aligned}
& \text { - } \frac{1}{M} \equiv\left\{\frac{1}{m_{i, j}}\right\}_{(i, j) \in[1, n] \times[1, p]}{ }^{\prime} \\
& \text { - } \exp M \equiv\left\{\exp m_{i, j}\right\}_{(i, j) \in[1, n] \times[1, p]^{\prime}} \\
& \text { - } \log M \equiv\left\{\log m_{i, j}\right\}_{(i, j) \in[1, n] \times[1, p]^{\prime}} \\
& \text { - } \sqrt{M} \equiv\left\{{\sqrt{m_{i, j}}}_{(i, j) \in[1, n] \times[1, p]^{\prime}}\right.
\end{aligned}
$$

where $M$ is a matrix of dimension $n \times p$ and where the $m_{i, j}$ 's are its components, i.e. $M=\left\{m_{i, j}\right\}_{(i, j) \in[1, n] \times[1, p]}$. These notations are consistent with programming language such as the one used by the R software. Besides, if $\alpha$ is a scalar, then $M+\alpha \equiv\left\{\alpha+m_{i, j}\right\}_{(i, j) \in[1, n] \times[1, p]}$. 
A.3. Discretized stochastic discount factor and real short-term rate. The Online Appendix I.1 shows that we have:

$$
M_{t, t+1}=\exp \left(\log (\delta)-\gamma \mathbb{E}(\Delta c)-\gamma\left[\mu^{\prime}\left(z_{t+1}-z_{t}\right)+\frac{1}{\lambda^{\prime} z_{t}}\left(\mu^{\prime} z_{t+1}-(1-\phi) \bar{s}-\phi \mu^{\prime} z_{t}\right)\right]\right) .
$$

From this, one can deduce the following expression for the real short-term rate:

$$
\begin{aligned}
r_{t}= & \mu_{r}^{\prime} z_{t} \\
\text { with } \quad \mu_{r}= & -\log (\delta)+\gamma \mathbb{E}(\Delta c)-\gamma(1-\phi) \bar{s} \frac{1}{\lambda}-\gamma \mu-\gamma \phi \frac{\mu}{\lambda} \\
& -\log \left[\left(\Pi \odot \exp \left[-\gamma \mu\left(\mathbf{1}+\frac{1}{\lambda}\right)^{\prime}\right]\right) \mathbf{1}\right] .
\end{aligned}
$$

A.4. Risk-neutral dynamics. The risk-neutral dynamics of $z_{t}$ is defined through:

$$
\mathbb{E}_{t}^{\mathrm{Q}}\left(z_{t+1}\right)=\mathbb{E}_{t}\left(\frac{M_{t, t+1}}{\mathbb{E}_{t} M_{t, t+1}} z_{t+1}\right)=\underbrace{\left(\frac{\exp \left(-\gamma\left\{1+\frac{1}{\lambda}\right\} \mu^{\prime}\right)}{\left[\exp \left(-\gamma\left\{1+\frac{1}{\lambda}\right\} \mu^{\prime}\right) \odot \Pi\right] \mathbf{1 1}^{\prime}} \odot \Pi\right)^{\prime}}_{=Q^{\prime}} z_{t}
$$

$Q$, is the risk-neutral equivalent of $\Pi=\left\{p_{i, j}\right\}_{i, j \in[1, N]}$, the matrix of (physical) transition probabilities (see A.1). The derivation of $Q$ is detailed in Online Appendix I.2.

\section{APPENDIX B. ASSET-PRICING FORMULA}

B.1. The term structure of real yields. Online Appendix I.3 shows that we have

$$
r_{t, h}=-\frac{1}{h} \log P_{t, h}^{r}
$$

where $P_{t, h}^{r}$, the date- $t$ price of a maturity- $h$ zero-coupon ILB is given by:

$$
P_{t, h}^{r}=\left(\left\{Q \times \operatorname{Diag}\left[\exp \left(-\mu_{r}\right)\right]\right\}^{h-1} \exp \left(-\mu_{r}\right)\right)^{\prime} z_{t} .
$$

B.2. The term structure of nominal yields. If $P_{t, h-1}^{n}=\exp \left(-b_{h-1} \pi_{t}\right) F_{h-1}^{n}{ }^{\prime} z_{t}$, Online Appendix I.4 shows that we then have $P_{t, h}^{n}=\exp \left(-b_{h} \pi_{t}\right) F_{h}^{n \prime} z_{t}$, with

$$
\left\{\begin{aligned}
F_{h}^{n}= & -\left(b_{h-1}+1\right) \bar{\pi}(1-\psi)+\frac{\left(b_{h-1}+1\right)^{2} \sigma_{\pi}^{2}}{2}+ \\
& \left(\exp \left[\left(-\mu_{r}+\rho_{\pi}\left(b_{h-1}+1\right) \frac{(1-\phi) \bar{s}}{\lambda}+\rho_{\pi}\left(b_{h-1}+1\right) \phi_{\frac{\mu}{\lambda}}\right) \mathbf{1}^{\prime}-\rho_{\pi}\left(b_{h-1}+1\right) \frac{1}{\lambda} \mu^{\prime}\right] \odot Q\right) F_{h-1}^{n} \\
b_{h}= & \left(b_{h-1}+1\right) \psi .
\end{aligned}\right.
$$

Nominal bond prices can therefore be computed by recursively employing the previous formulas, using the initial conditions $b_{0}=0$ and $F_{0}^{n}=\mathbf{1}$. Yields-to-maturity are further obtained as:

$$
i_{t, h}=\frac{b_{h}}{h} \pi_{t}-\frac{1}{h} \log \left(F_{h}^{n}\right)^{\prime} z_{t} .
$$


B.3. The term structure of GDP-linked bond yields. Let us denote by $P_{t, h}^{*}$ the date- $t$ price of a maturity$h$ bond indexed on nominal GDP. Online Appendix I.5 shows that:

$$
P_{t, h}^{*}=\left(H^{h} \mathbf{1}\right)^{\prime} z_{t}
$$

with

$$
H=\frac{1}{\mathbb{E} \exp \left(\rho_{y} v\right)}\left(\exp \left[\left(-\mu_{r}-\frac{(1-\phi) \rho_{y} \bar{s}}{\lambda}-\rho_{y} \phi \frac{\mu}{\lambda}\right) \mathbf{1}^{\prime}+\frac{\rho_{y}}{\lambda} \mu^{\prime}\right] \odot Q\right) .
$$

As a result:

$$
r_{t, h}^{*}=-\frac{1}{h} \log \left(H^{h} \mathbf{1}\right)^{\prime} z_{t}
$$

B.4. Stock returns. As is common in the asset-pricing literature (Abel, 1999; Bansal and Yaron, 2004; Wachter, 2013), we define the equity - or stock - as a claim to future dividends $\operatorname{Div}_{t+h}, h=0,1, \ldots$ (see Eq. 19 for the specification of the dividend growth rate). Online Appendix I.6 shows that, under a no-bubble transversality condition, the date- $t$ price of this asset, denoted by $P_{t}$, satisfies:

$$
\frac{P_{t}^{d}}{\operatorname{Div}_{t}}=[\underbrace{(I d-J)^{-1} J \mathbf{1}}_{=: \chi}]^{\prime} z_{t}
$$

where

$$
J=\exp \left(\overline{\operatorname{div}}+\frac{\sigma_{d}^{2}}{2}\right)\left(\exp \left[\left(-\mu_{r}-\frac{(1-\phi) \rho_{d} \bar{s}}{\lambda}-\rho_{d} \phi \frac{\mu}{\lambda}\right) \mathbf{1}^{\prime}+\frac{\rho_{d}}{\lambda} \mu^{\prime}\right] \odot Q\right) .
$$

Besides, the stock return is given by:

$$
\frac{P_{t+1}^{d}+D i v_{t+1}}{P_{t}^{d}}-1=\exp \left(\varepsilon_{t+1}^{d}-\frac{\sigma_{d}^{2}}{2}\right) z_{t}^{\prime} M z_{t+1}-1 .
$$

where

$$
M=\exp \left(\overline{\operatorname{div}}+\frac{\sigma_{d}^{2}}{2}\right)\left\{\exp \left[\frac{1}{\lambda} \mu^{\prime}-\left(\frac{(1-\phi) \bar{s}}{\lambda}+\phi \frac{\mu}{\lambda}\right) \mathbf{1}^{\prime}\right] \odot \frac{\mathbf{1}^{\prime}+\chi^{\prime}}{\chi}\right\}
$$

Therefore:

$$
\mathbb{E}_{t}\left(\frac{P_{t+1}^{d}+\operatorname{Div}_{t+1}}{P_{t}^{d}}-1\right)=\mathbf{1}^{\prime}(M \odot \Pi)^{\prime} z_{t}-1
$$

\section{APPENDIX C. DeBT DYNAMICS}

Eq. (8) boils down to:

$$
D_{t}=\sum_{h=1}^{H} \sum_{k=0}^{h-1} I_{t-k, h}^{n} e^{k i_{t-k, h}}+I_{t-k, h}^{r} e^{k\left[r_{t-k, h}+\pi_{t-k, t}\right]}+I_{t-k, h}^{*} e^{k\left[r_{t-k, h}^{*}+\left(y_{t-k, t}-y_{t-k, h}^{e}\right)+\pi_{t-k, t}\right]} .
$$


On date $t$, the government has to repay the following amount:

$$
\begin{gathered}
R_{t}=\sum_{h=1}^{H} I_{t-h, h}^{n} \exp \left(h i_{t-h, h}\right)+I_{t-h, h}^{r} \exp \left(h\left[r_{t-h, h}+\pi_{t-h, t}\right]\right)+ \\
I_{t-h, h}^{*} \exp \left(h\left[r_{t-h, h}^{*}+\left(y_{t-h, t}-y_{t-h, h}^{e}\right)+\pi_{t-h, t}\right]\right) .
\end{gathered}
$$

Eq. (a.8) and (a.9) imply that:

$$
\begin{aligned}
D_{t}= & \sum_{h=1}^{H} \sum_{k=0}^{h} I_{t-k, h}^{n} e^{k i_{t-k, h}}+I_{t-k, h}^{r} e^{k\left[r_{t-k, h}+\pi_{t-k, t}\right]}+I_{t-k, h}^{*} e^{k\left[r_{t-k, h}^{*}+\left(y_{t-k, t}-y_{t-k, h}^{e}\right)+\pi_{t-k, t}\right]} \\
& -R_{t} .
\end{aligned}
$$

From a cash flow perspective, on every date, the amount issued by the government has to equate the value of maturing debt, net of budget surplus $\left(B S_{t}\right)$. That is:

$$
\sum_{h=1}^{H} I_{t, h}^{n}+I_{t, h}^{r}+I_{t, h}^{*}=R_{t}-B S_{t} .
$$

Combined with Eq. (a.10), the previous equation gives:

$$
\begin{aligned}
D_{t}= & \sum_{h=1}^{H} \sum_{k=1}^{h} I_{t-k, h}^{n} e^{k i_{t-k, h}}+I_{t-k, h}^{r} e^{k\left[r_{t-k, h}+\pi_{t-k, t}\right]}+I_{t-k, h}^{*} e^{k\left[r_{t-k, h}^{*}+\left(y_{t-k, t}-y_{t-k, h}^{e}\right)+\pi_{t-k, t}\right]} \\
& -B S_{t} .
\end{aligned}
$$

Using the notations $d_{t}=D_{t} /\left(Y_{t} P_{t}\right), b s_{t}=B S_{t} /\left(Y_{t} P_{t}\right), i s s_{t, k}^{n}=I_{t, k}^{n} /\left(Y_{t} P_{t}\right), i s s_{t, k}^{r}=I_{t, k}^{r} /\left(Y_{t} P_{t}\right)$ and $i s s_{t, k}^{*}=I_{t, k}^{*} /\left(Y_{t} P_{t}\right)$, Eq. (a.12) reads:

$$
\begin{aligned}
d_{t}= & \sum_{h=1}^{H} \sum_{k=1}^{h} i s s_{t-k, h}^{n} e^{k\left[i_{t-k, h}-y_{t-k, t}-\pi_{t-k, t}\right]}+i s s_{t-k, h}^{r} e^{k\left[r_{t-k, h}-y_{t-k, t}\right]}+i s s_{t-k, h}^{*} e^{k\left[r_{t-k, h}^{*}-y_{t-k, h}^{e}\right]} \\
& -b s_{t} .
\end{aligned}
$$

Besides, for date $t-1$, Eq. (a.8) becomes:

$$
\begin{aligned}
d_{t-1}= & \sum_{h=1}^{H} \sum_{k=0}^{h-1} i s s_{t-1-k, h}^{n} e^{k\left[i_{t-1-k, h}-y_{t-1-k, t-1}-\pi_{t-1-k, t-1}\right]}+ \\
& \sum_{h=1}^{H} \sum_{k=0}^{h-1} i s s_{t-1-k, h}^{r} e^{k\left[r_{t-1-k, h}-y_{t-1-k, t-1}\right]}+\sum_{h=1}^{H} \sum_{k=0}^{h-1} i s s_{t-1-k, h}^{*} e^{\left.k\left[r_{t-1-k, h}^{*}-y_{t-1-k, h}^{e}\right)\right]} \\
= & \sum_{h=1}^{H} \sum_{k=1}^{h} i s s_{t-k, h}^{n} e^{(k-1)\left[i_{t-k, h}-y_{t-k, t-1}-\pi_{t-k, t-1}\right]}+ \\
& \sum_{h=1}^{H} \sum_{k=1}^{h} i s s_{t-k, h}^{r} e^{(k-1)\left[r_{t-k, h}-y_{t-k, t-1}\right]}+\sum_{h=1}^{H} \sum_{k=1}^{h} i s s_{t-k, h}^{*} e^{\left.(k-1)\left[r_{t-k, h}^{*}-y_{t-k, h}^{e}\right)\right]} .
\end{aligned}
$$

Subtracting Eq. (a.14) from Eq. (a.13) finally leads to Eq. (9). 
Using Eq. (a.9), let us express Eq. (a.11) in terms of fractions of nominal GDP:

$$
\begin{aligned}
& \underbrace{\sum_{h=1}^{H} i s s_{t, h}^{n}+i s s_{t, h}^{r}+i s s_{t, h}^{*}}_{\text {Debt issued on date } t}=-b s_{t}+ \\
& \underbrace{\sum_{h=1}^{H} i s s_{t-h, h}^{n} e^{h\left[i_{t-h, h}-y_{t-h, t}-\pi_{t-h, t}\right]}+i s s_{t-h, h}^{r} e^{h\left[r_{t-h, h}-y_{t-h, t}\right]}+i s s_{t-h, h}^{*} e^{h\left[r_{t-h, h}^{*}-y_{t-h, h}^{e}\right]}}_{\text {Debt maturing on date } t} .
\end{aligned}
$$

\section{REFERENCES}

Abel, Andrew B. 1999. "Risk Premia and Term Premia in General Equilibrium." Journal of Monetary Economics 43 (1):3-33.

Angeletos, George-Marios. 2002. "Fiscal Policy with Noncontingent Debt and the Optimal Maturity Structure." The Quarterly Journal of Economics 117 (3):1105-1131.

Athanasoulis, Stefano, Robert J. Shiller, and Eric Van Wincoop. 1999. “Macro Markets and Financial Security." FRBNY Economic Policy Review 1:21-39.

Ball, Ian and Gary Pflugrath. 2012. “Government Accounting: Making Enron Look Good." World Economics 13 (1):9-26.

Bank for International Settlements. 1999. Market Liquidity: Research Findings and Selected Policy Implications. No. 11 in CGFS Papers. Bank for International Settlements.

Bansal, R. and A. Yaron. 2004. "Risks for the Long Run: A Potential Resolution of Asset Pricing Puzzles." Journal of Finance 59:1481-1509.

Barr, David, Oliver Bush, and Alex Pienkowski. 2014. "GDP-Linked Bonds and Sovereign Default." Bank of England working papers 484, Bank of England.

Blanchard, Olivier J., Paolo Mauro, and Julien Acalin. 2016. "The Case for Growth-Indexed Bonds in Advanced Economies Today." Policy Briefs PB16-2, Peterson Institute for International Economics.

Bohn, Henning. 1990. "Tax Smoothing with Financial Instruments." American Economic Review 80 (5):1217-1230.

— 1998. "The Behavior of U.S. Public Debt and Deficits." The Quarterly Journal of Economics 113 (3):949-963.

Borensztein, Eduardo and Paolo Mauro. 2004. “The Case for GDP-Indexed Bonds." Economic Policy 19 (38):165-216.

Buera, Francisco and Juan Pablo Nicolini. 2004. “Optimal Maturity of Government Debt without State Contingent Bonds." Journal of Monetary Economics 51 (3):531-554. 
Caballero, Ricardo J., Emmanuel Farhi, and Pierre-Olivier Gourinchas. 2017. "The Safe Assets Shortage Conundrum." Journal of Economic Perspectives 31 (3):29-46.

Campbell, John Y. 2003. "Consumption-Based Asset Pricing." In Handbook of the Economics of Finance, Handbook of the Economics of Finance, vol. 1, edited by G.M. Constantinides, M. Harris, and R. M. Stulz, chap. 13. Elsevier, 803-887.

Campbell, John Y. and John Cochrane. 1999. “By Force of Habit: A Consumption-Based Explanation of Aggregate Stock Market Behavior." Journal of Political Economy 107 (2):205-251.

Chamon, Marcos, Alejo Costa, and Luca Ricci. 2008. "Is There a Novelty Premium on New Financial Instruments? The Argentine Experience with GDP-Indexed Warrants." IMF Working Papers 08/109, International Monetary Fund.

Chamon, Marcos and Paolo Mauro. 2006. "Pricing Growth-Indexed Bonds." Journal of Banking E Finance 30 (12):3349-3366.

Collin-Dufresne, Pierre, Michael Johannes, and Lars A. Lochstoer. 2016. “Parameter Learning in General Equilibrium: The Asset Pricing Implications." American Economic Review 106 (3):664-698.

D'Amico, Stefania, Don H. Kim, and Min Wei. 2018. “Tips from TIPS: The Informational Content of Treasury Inflation-Protected Security Prices." Journal of Financial and Quantitative Analysis 53 (1):395436.

Eguren-Martin, Fernando, Andrew Meldrum, and Wen Yan. 2020. “No-Arbitrage Pricing of GDPLinked Bonds." Bank of England working papers 849, Bank of England.

Faraglia, Elisa, Albert Marcet, and Andrew Scott. 2008. "Fiscal Insurance and Debt Management in OECD Economies." Economic Journal 118 (527):363-386.

—. 2010. "In Search of a Theory of Debt Management." Journal of Monetary Economics 57 (7):821-836.

Favero, Carlo, Alessandro Missale, and Gustavo Piga. 2000. “EMU and Public Debt Management: One Money, One Debt?" CEPR Policy Paper 3, CEPR.

Fratzscher, Marcel, Christoph Große-Steffen, and Malte Rieth. 2014. "GDP-Linked Loans for Greece." DIW Economic Bulletin 4 (9):40-49.

Ghosh, Atish, Jun I. Kim, Enrique Mendoza, Jonathan Ostry, and Mahvash Qureshi. 2013. "Fiscal Fatigue, Fiscal Space and Debt Sustainability in Advanced Economies." Economic Journal :F4-F30.

Ghosh, Atish R., Jonathan D. Ostry, and Mahvash S. Qureshi. 2013. “Fiscal Space and Sovereign Risk Pricing in a Currency Union." Journal of International Money and Finance 34:131 - 163.

Gürkaynak, Refet S., Brian Sack, and Jonathan H. Wright. 2007. “The U.S. Treasury yield curve: 1961 to the present." Journal of Monetary Economics 54 (8):2291-2304.

—. 2010. "The TIPS Yield Curve and Inflation Compensation." American Economic Journal: Macroeconomics 2 (1):70-92.

International Monetary Fund, Bank for International Settlements and European Central Bank. 2015. Handbook on Securities Statistics. ISBN: 978-1-49838-831-3. International Monetary Fund. 
International Monetary Funds. 2017. “State-Contingent Debt Instruments for Sovereigns." Policy paper, IMF.

Kamstra, Mark J. and Robert J. Shiller. 2009. "The Case for Trills: Giving the People and Their Pension Funds a Stake in the Wealth of the Nation." Cowles Foundation Discussion Papers 1717, Cowles Foundation for Research in Economics, Yale University.

Lledó, Victor, Sungwook Yoon, Xiangming Fang, Samba Mbaye, and Young Kim. 2017. "Fiscal Rules at a Glance." Tech. rep., International Monetary Fund.

Mendoza, Enrique G. and Jonathan D. Ostry. 2008. “International Evidence on Fiscal Solvency: Is Fiscal Policy “Responsible"?" Journal of Monetary Economics 55 (6):1081-1093.

Mylonas, Paul, Sebastian Schich, Thorsteinn Thorgeirsson, and Gert Wehinger. 2000. "New Issues in Public Debt Management: Government Surpluses in Several OECD Countries, the Common Currency in Europe and Rapidly Rising Debt in Japan." OECD Economics Department Working Papers 239, OECD Publishing.

OECD. 2018. Sovereign Borrowing Outlook 2018. OECD.

Piazzesi, Monika and Martin Schneider. 2007. "Equilibrium Yield Curves." In NBER Macroeconomics Annual 2006, Volume 21, NBER Chapters. National Bureau of Economic Research, Inc, 389-472.

Pisani-Ferry, Jean, Erkki Vihriälä, and Guntram B. Wolff. 2013. “Options for a Euro-Area Fiscal Capacity." Policy Contributions 765, Bruegel.

Sandleris, Guido and Mark J.L Wright. 2013. “GDP-Indexed Bonds: A Tool to Reduce Macroeconomic Risk?" Business School Working Papers 2013-02, Universidad Torcuato Di Tella.

Seo, Sang Byung and Jessica A. Wachter. 2018. “Do Rare Events Explain CDX Tranche Spreads?” Journal of Finance 73:2343-2383.

Serafeim, George. 2015. “Greece's Debt: Sustainable?" Harvard Business School Case 115-063.

Shen, Pu. 2009. “Developing a Liquid Market for Inflation-Indexed Government Securities: Lessons from Earlier Experiences." Economic Review (I):89-113.

Shiller, Robert. 2015. Irrational Exuberance. Princeton University Press, 3 ed.

Soll, Jacob. 2015. “Greece's Accounting Problem." The New York Times, 20 Jan. 2015 URL https: //www.nytimes.com/2015/01/21/opinion/greeces-accounting-problem.html.

System of National Accounts. 2008. System of National Accounts 2008. New York: United Nations, European Commission, Inter- national Monetary Fund, Organisation for Economic Cooperation and Development, and World Bank. URL unstats.un.org/unsd/nationalaccount/docs/ SNA2008.pdf.

Wachter, Jessica A. 2005. "Solving Models with External Habit." Finance Research Letters 2 (4):210-226.

- 2006. "A Consumption-Based Model of the Term Structure of Interest Rates." Journal of Financial Economics 79 (2):365-399. 
. 2013. “Can Time-Varying Risk of Rare Disasters Explain Aggregate Stock Market Volatility?" Journal of Finance 68 (3):987-1035.

Wright, Chris and John Joisce. 2001. "Statistical Treatment of Accrual of Interest on Debt Securities." IMF Working Papers 01/132, International Monetary Fund.

Yared, Pierre. 2019. "Rising Government Debt: Causes and Solutions for a Decades-Old Trend." Journal of Economic Perspectives 33 (2):115-140. 


\section{Online Appendix}

\section{Taming Debt: Can GDP-Linked Bonds do the Trick?}

Sarah MouABBI, Jean-Paul RENNE, Jean-Guillaume SAHUC

\section{APPENDIX I. PRICING FORMULA}

I.1. Discretized stochastic discount factor and real short-term risk-free rate. We have:

$$
\begin{aligned}
M_{t, t+1} & =\exp \left(\log (\delta)-\gamma\left[\mu\left(z_{t+1}-z_{t}\right)+c_{t+1}-\mathbb{E}_{t}\left(c_{t+1}\right)+\mathbb{E}_{t}\left(c_{t+1}\right)-c_{t}\right]\right) \\
& =\exp \left(\log (\delta)-\gamma\left[\mu^{\prime}\left(z_{t+1}-z_{t}\right)+\frac{1}{\lambda^{\prime} z_{t}}\left(\mu^{\prime} z_{t+1}-(1-\phi) \bar{s}-\phi \mu^{\prime} z_{t}\right)+\mathbb{E}_{t}\left(c_{t+1}\right)-c_{t}\right]\right) \\
& =\exp \left(\log (\delta)-\gamma \mathbb{E}(\Delta c)-\gamma\left[\mu^{\prime}\left(z_{t+1}-z_{t}\right)+\frac{1}{\lambda^{\prime} z_{t}}\left(\mu^{\prime} z_{t+1}-(1-\phi) \bar{s}-\phi \mu^{\prime} z_{t}\right)\right]\right) .
\end{aligned}
$$

Hence

$$
\begin{aligned}
\exp \left(-r_{t}\right):= & \mathbb{E}_{t}\left(M_{t, t+1}\right) \\
= & \exp \left[\log (\delta)-\gamma \mathbb{E}(\Delta c)+\gamma(1-\phi) \bar{s}\left(\frac{1}{\lambda}\right)^{\prime} z_{t}+\gamma \mu^{\prime} z_{t}+\gamma \phi\left(\frac{\mu}{\lambda}\right)^{\prime} z_{t}\right] \times \\
& \mathbb{E}_{t}\left(\exp \left(-\gamma\left[\mu^{\prime} z_{t+1}+\frac{\mu^{\prime} z_{t+1}}{\lambda^{\prime} z_{t}}\right]\right)\right) \\
= & \exp \left[\log (\delta)-\gamma \mathbb{E}(\Delta c)+\gamma(1-\phi) \bar{s}\left(\frac{1}{\lambda}\right)^{\prime} z_{t}+\gamma \mu^{\prime} z_{t}+\gamma \phi\left(\frac{\mu}{\lambda}\right)^{\prime} z_{t}\right] \times \\
& \mathbb{E}_{t}\left(\exp \left(z_{t}^{\prime}\left[-\gamma\left(\mathbf{1}+\frac{1}{\lambda}\right) \mu^{\prime}\right] z_{t+1}\right)\right) \\
= & \exp \left[\log (\delta)-\gamma \mathbb{E}(\Delta c)+\gamma(1-\phi) \bar{s}\left(\frac{1}{\lambda}\right)^{\prime} z_{t}+\gamma \mu^{\prime} z_{t}+\gamma \phi\left(\frac{\mu}{\lambda}\right)^{\prime} z_{t}\right] \times \\
& z_{t}^{\prime} \exp \left(\left[-\gamma\left(\mathbf{1}+\frac{1}{\lambda}\right) \mu^{\prime}\right]\right) \Pi^{\prime} z_{t} .
\end{aligned}
$$

Therefore, $r_{t}=\mu_{r}^{\prime} z_{t}$ with:

$$
\begin{aligned}
\mu_{r}= & -\log (\delta)+\gamma \mathbb{E}(\Delta c)-\gamma(1-\phi) \bar{s} \frac{1}{\lambda}-\gamma \mu-\gamma \phi \frac{\mu}{\lambda} \\
& -\log \left[\left(\Pi \odot \exp \left[-\gamma \mu\left(\mathbf{1}+\frac{1}{\lambda}\right)^{\prime}\right]\right) \mathbf{1}\right] .
\end{aligned}
$$


I.2. Risk-neutral dynamics of $z_{t}$. From (oa.1), we obtain:

$$
\begin{aligned}
\frac{M_{t, t+1}}{\mathbb{E}_{t} M_{t, t+1}} & =\frac{\exp \left(-\gamma \mu^{\prime} z_{t+1}-\gamma \frac{\mu^{\prime} z_{t+1}}{\lambda^{\prime} z_{t}}\right)}{\mathbb{E}_{t}\left[\exp \left(-\gamma \mu^{\prime} z_{t+1}-\gamma \frac{\mu^{\prime} z_{t+1}}{\lambda^{\prime} z_{t}}\right)\right]}=\frac{z_{t}^{\prime} \exp \left(-\gamma\left\{1+\frac{1}{\lambda}\right\} \mu^{\prime}\right) z_{t+1}}{z_{t}^{\prime}\left[\exp \left(-\gamma\left\{1+\frac{1}{\lambda}\right\} \mu^{\prime}\right) \odot \Pi\right] \mathbf{1}} \\
& =z_{t}^{\prime} \frac{\exp \left(-\gamma\left\{1+\frac{1}{\lambda}\right\} \mu^{\prime}\right)}{\left[\exp \left(-\gamma\left\{1+\frac{1}{\lambda}\right\} \mu^{\prime}\right) \odot \Pi\right] \mathbf{1 1}^{\prime}} z_{t+1} .
\end{aligned}
$$

Therefore:

$$
\begin{aligned}
\mathbb{E}_{t}^{\mathrm{Q}}\left(z_{t+1}\right) & =\mathbb{E}_{t}\left(\frac{M_{t, t+1}}{\mathbb{E}_{t} M_{t, t+1}} z_{t+1}\right) \\
& =\mathbb{E}_{t}\left(\left[z_{t}^{\prime} \frac{\exp \left(-\gamma\left\{1+\frac{1}{\lambda}\right\} \mu^{\prime}\right)}{\left.\exp \left(-\gamma\left\{1+\frac{1}{\lambda}\right\} \mu^{\prime}\right) \odot \Pi\right] \mathbf{1 1}^{\prime}} z_{t+1}\right) z_{t+1}\right) \\
& =\left[\frac{\left.z_{t}^{\prime}\left(\frac{\exp \left(-\gamma\left\{1+\frac{1}{\lambda}\right\} \mu^{\prime}\right)}{\left[\exp \left(-\gamma\left\{1+\frac{1}{\lambda}\right\} \mu^{\prime}\right) \odot \Pi\right] \mathbf{1 1}^{\prime}} \odot \Pi\right)\right]^{\prime}}{\left[\exp \left(-\gamma\left\{1+\frac{1}{\lambda}\right\} \mu^{\prime}\right)\right.}\right)^{\prime} z_{t}=: Q^{\prime} z_{t} . \\
& \left.=\left(-\gamma\left\{1+\frac{1}{\lambda}\right\} \mu^{\prime}\right) \odot \Pi\right] \mathbf{1 1}^{\prime}
\end{aligned}
$$

\section{I.3. Inflation-linked bonds}

Let us denote $P_{t, h}^{r}$ the date- $t$ price of a maturity- $h$ zero-coupon ILB. We have:

$$
\begin{aligned}
P_{t, h}^{r} & =\exp \left(-\mu_{r}^{\prime} z_{t}\right) \mathbb{E}_{t}^{\mathrm{Q}}\left(P_{t+1, h-1}^{r}\right) \\
& =\mathbb{E}_{t}^{\mathrm{Q}}\left[\exp \left(-\mu_{r}^{\prime} z_{t}-\mu_{r}^{\prime} z_{t+1}-\cdots-\mu_{r}^{\prime} z_{t+h-1}\right)\right] \\
& =\exp \left(-\mu_{r}\right)^{\prime}\left\{\operatorname{Diag}\left[\exp \left(-\mu_{r}\right)\right] Q^{\prime}\right\}^{h-1} z_{t} \\
& =\left(\left\{Q \times \operatorname{Diag}\left[\exp \left(-\mu_{r}\right)\right]\right\}^{h-1} \exp \left(-\mu_{r}\right)\right)^{\prime} z_{t}=: F_{h}^{r \prime} z_{t} .
\end{aligned}
$$

\section{I.4. Nominal bonds}


Assume that $P_{t, h-1}^{n}=\exp \left(-b_{h-1} \pi_{t}\right) F_{h-1}^{n}{ }^{\prime} z_{t}$. We then have:

$$
\begin{aligned}
& P_{t, h}^{n}=\exp \left(-\mu_{r}^{\prime} z_{t}\right) \mathbb{E}_{t}^{\mathrm{Q}}\left[\exp \left(-\pi_{t+1}\right) P_{t+1, h-1}^{n}\right] \\
= & \exp \left(-\mu_{r}^{\prime} z_{t}\right) \mathbb{E}_{t}^{\mathrm{Q}}\left[\exp \left(\left[-b_{h-1}-1\right] \pi_{t+1}\right) F_{h-1}^{n}{ }^{\prime} z_{t+1}\right] \\
= & \exp \left(-\mu_{r}^{\prime} z_{t}\right) \mathbb{E}_{t}^{\mathrm{Q}}\left[\exp \left(\left[-b_{h-1}-1\right]\left[\bar{\pi}(1-\psi)+\psi \pi_{t}+\varepsilon^{\pi}{ }_{t+1}+\rho_{\pi}\left(c_{t+1}-\mathbb{E}_{t}\left(c_{t+1}\right)\right)\right]\right) F_{h-1}^{n} z_{t+1}\right] \\
= & \exp \left(-\mu_{r}^{\prime} z_{t}+\left(-b_{h-1}-1\right)\left[\bar{\pi}(1-\psi)+\psi \pi_{t}\right]+\frac{\left(b_{h-1}+1\right)^{2} \sigma_{\pi}^{2}}{2}\right) \times \\
& \mathbb{E}_{t}^{\mathrm{Q}}\left(\exp \left(\rho_{\pi}\left(-b_{h-1}-1\right)\left[c_{t+1}-\mathbb{E}_{t}\left(c_{t+1}\right)\right]\right) F_{h-1}^{n}{ }^{\prime} z_{t+1}\right) \\
= & \exp \left(-\mu_{r}^{\prime} z_{t}+\left(-b_{h-1}-1\right)\left[\bar{\pi}(1-\psi)+\psi \pi_{t}\right]+\frac{\left(b_{h-1}+1\right)^{2} \sigma_{\pi}^{2}}{2}\right) \times \\
& \mathbb{E}_{t}^{\mathrm{Q}}\left(\exp \left(\rho_{\pi}\left(-b_{h-1}-1\right)\left[\frac{1}{\lambda^{\prime} z_{t}}\left(\mu^{\prime} z_{t+1}-(1-\phi) \bar{s}-\phi \mu^{\prime} z_{t}\right)\right]\right) F_{h-1}^{n} z_{t+1}\right) \\
= & \exp \left[-\left(b_{h-1}+1\right) \psi \pi_{t}\right] \times \\
& \exp \left(-\left(b_{h-1}+1\right) \bar{\pi}(1-\psi)+\frac{\left(b_{h-1}+1\right)^{2} \sigma_{\pi}^{2}}{2}\right) \times \\
& \left\{\left(\exp \left[\left(-\mu_{r}+\rho_{\pi}\left(b_{h-1}+1\right) \frac{(1-\phi) \bar{s}}{\lambda}+\rho_{\pi}\left(b_{h-1}+1\right) \phi \frac{\mu}{\lambda}\right) \mathbf{1}^{\prime}-\rho_{\pi}\left(b_{h-1}+1\right) \frac{1}{\lambda} \mu^{\prime}\right] \odot Q^{\prime}\right) F_{h-1}^{n}\right\}^{\prime} z_{t} .
\end{aligned}
$$

\section{I.5. GDP-linked bonds}

Because the $Y_{t} / Y_{t-1}$ s are i.i.d., we have:

$$
\begin{aligned}
\frac{Y_{t+h} / Y_{t}}{\mathbb{E}_{t}\left(Y_{t+h} / Y_{t}\right)} & =\frac{Y_{t+h} / Y_{t+h-1}}{\mathbb{E}_{t}\left(Y_{t+h} / Y_{t+h-1}\right)} \times \cdots \times \frac{Y_{t+1} / Y_{t}}{\mathbb{E}_{t}\left(Y_{t+1} / Y_{t}\right)} \\
& =\exp \left(\Delta y_{t+1}+\cdots+\Delta y_{t+h}-h \log \mathbb{E} \exp [\Delta y]\right) \\
& =\exp \left(\rho_{y}\left[v_{t+1}+\cdots+v_{t+h}\right]-h \log \mathbb{E} \exp [v]-h \frac{\sigma_{y}^{2}}{2}\right)
\end{aligned}
$$

Consider a maturity- $h$ bond indexed on nominal GDP issued on date $t$ (call it bond A). This bond provides the real payoff $\frac{Y_{t+h}}{Y_{t}} /\left(\mathbb{E}_{t}\left[\frac{Y_{t+h}}{Y_{t}}\right]\right)$ on date $t+h$. Now, consider a bond indexed on nominal GDP indexed on date $t+1$ but with maturity $h-1$ (call it bond B). Bond B provides the real payoff $\frac{Y_{t+h}}{Y_{t+1}} /\left(\mathbb{E}_{t+1}\left[\frac{Y_{t+h}}{Y_{t+1}}\right]\right)$ on date $t+h$. Therefore, on date $t+h$, the payoff of bond $\mathrm{A}$ is equal to that of bond B multiplied by:

$$
\frac{Y_{t+h}}{Y_{t}} /\left(\mathbb{E}_{t}\left[\frac{Y_{t+h}}{Y_{t}}\right]\right) /\left\{\frac{Y_{t+h}}{Y_{t+1}} /\left(\mathbb{E}_{t+1}\left[\frac{Y_{t+h}}{Y_{t+1}}\right]\right)\right\}=\frac{Y_{t+1}}{Y_{t}} \frac{1}{\operatorname{E} \exp (\Delta y)}
$$

Hence, denoting by $P_{t, h}^{*}$ the date- $t$ price of a maturity- $h$ bond indexed on nominal GDP we have:

$$
P_{t, h}^{*}=\frac{1}{\mathbb{E} \exp (\Delta y)} \exp \left(-\mu_{r}^{\prime} z_{t}\right) \mathbb{E}_{t}^{\mathbb{Q}}\left(\exp \left[\bar{y}+\rho_{y} v_{t+1}+\varepsilon_{t+1}^{y}\right] P_{t+1, h-1}^{*}\right),
$$


and, as a result:

$$
\begin{aligned}
P_{t, h}^{*} & =\frac{\exp \left(g_{y}+\frac{\sigma_{y}^{2}}{2}\right)}{\mathbb{E} \exp (\Delta y)} \exp \left(-\mu_{r}^{\prime} z_{t}\right) \mathbb{E}_{t}^{\mathrm{Q}}\left(\exp \left[\rho_{y} v_{t+1}\right] P_{h-1}^{*} z_{t+1}\right) \\
& =\frac{1}{\operatorname{E} \exp \left(\rho_{y} v\right)} \exp \left(-\mu_{r}^{\prime} z_{t}\right) \mathbb{E}_{t}^{\mathrm{Q}}\left(\exp \left[\frac{\rho_{y}}{\lambda^{\prime} z_{t}}\left(\mu^{\prime} z_{t+1}-(1-\phi) \bar{s}-\phi \mu^{\prime} z_{t}\right)\right] P_{h-1}^{*} z_{t+1}\right) \\
& =\frac{1}{\mathbb{E} \exp \left(\rho_{y} v\right)} \exp \left(-\mu_{r}^{\prime} z_{t}+\frac{\rho_{y}}{\lambda^{\prime} z_{t}}\left(-(1-\phi) \bar{s}-\phi \mu^{\prime} z_{t}\right)\right) \mathbb{E}_{t}^{\mathrm{Q}}\left(\exp \left[\frac{\rho_{y} \mu^{\prime} z_{t+1}}{\lambda^{\prime} z_{t}}\right] P_{h-1}^{*} z_{t+1}\right) \\
& =\frac{1}{\mathbb{E} \exp \left(\rho_{y} v\right)} \exp \left(-\mu_{r}^{\prime} z_{t}+\frac{\rho_{y}}{\lambda^{\prime} z_{t}}\left(-(1-\phi) \bar{s}-\phi \mu^{\prime} z_{t}\right)\right) \mathbb{E}_{t}^{\mathrm{Q}}\left(z_{t}^{\prime}\left(\exp \left[\frac{\rho_{y}}{\lambda} \mu^{\prime}\right] \odot \mathbf{1} P_{h-1}^{*}\right) z_{t+1}\right) \\
& =\frac{1}{\mathbb{E} \exp \left(\rho_{y} v\right)} \exp \left(-\mu_{r}^{\prime} z_{t}+\frac{\rho_{y}}{\lambda^{\prime} z_{t}}\left(-(1-\phi) \bar{s}-\phi \mu^{\prime} z_{t}\right)\right) z_{t}^{\prime}\left(\exp \left[\frac{1}{\lambda} \mu^{\prime}\right] \odot \mathbf{1} P_{h-1}^{*}\right) Q^{\prime} z_{t} \\
& =\frac{1}{\operatorname{E} \exp \left(\rho_{y} v\right)} \exp \left(-\left[\mu_{r}+\frac{(1-\phi) \rho_{y} \bar{s}}{\lambda}+\frac{\rho_{y} \phi \mu}{\lambda}\right]^{\prime} z_{t}\right) \operatorname{diag}\left[\left(\exp \left[\frac{\rho_{y}}{\lambda} \mu^{\prime}\right] \odot \mathbf{1} P_{h-1}^{*}\right) Q^{\prime}\right]^{\prime} z_{t} \\
& =\frac{1}{\mathbb{E} \exp \left(\rho_{y} v\right)} \exp \left(-\left[\mu_{r}+\frac{(1-\phi) \rho_{y} \bar{s}}{\lambda}+\frac{\rho_{y} \phi \mu}{\lambda}\right]^{\prime} z_{t}\right)\left(\left[\exp \left[\frac{\rho_{y}}{\lambda} \mu^{\prime}\right] \odot \mathbf{1} P_{h-1}^{*} \odot Q^{Q}\right]\right)^{\prime} z_{t} \\
& =\frac{1}{\operatorname{E} \exp \left(\rho_{y} v\right)}\left(\left[\exp \left(-\left[\mu_{r}+\frac{(1-\phi) \rho_{y} \bar{s}}{\lambda}+\frac{\rho_{y} \phi \mu}{\lambda}\right] \mathbf{1}^{\prime}+\frac{\rho_{y}}{\lambda} \mu^{\prime}\right) \odot \mathbf{1} P_{h-1}^{*} \odot Q^{\prime}\right]^{\mathbf{1}}\right)^{\prime} z_{t} \\
& =\frac{1}{\operatorname{E} \exp \left(\rho_{y} v\right)}\left(\left[\exp \left(-\left[\mu_{r}+\frac{(1-\phi) \rho_{y} \bar{s}}{\lambda}+\frac{\rho_{y} \phi \mu}{\lambda}\right] \mathbf{1}^{\prime}+\frac{\rho_{y}}{\lambda} \mu^{\prime}\right) \odot Q\right] P_{h-1}^{*}\right)^{\prime} z_{t} .
\end{aligned}
$$

Hence, if $P_{t, h-1}^{*}=F_{h-1}^{*}{ }^{\prime} z_{t}$, we obtain $P_{t, h}^{*}=F_{h}^{* \prime} z_{t}$ with

$$
\begin{aligned}
F_{h}^{*} & =\underbrace{\frac{1}{\mathbb{E} \exp \left(\rho_{y} v\right)}\left(\exp \left[\left(-\mu_{r}-\frac{(1-\phi) \rho_{y} \bar{s}}{\lambda}-\rho_{y} \phi \frac{\mu}{\lambda}\right) \mathbf{1}^{\prime}+\frac{\rho_{y}}{\lambda} \mu^{\prime}\right] \odot Q\right)}_{=: H} F_{h-1}^{*} \\
& =H^{h} \mathbf{1} .
\end{aligned}
$$

\section{I.6. Stock returns}

We want to price the asset that delivers $\mathrm{Div}_{t}$ on each period $t$; this asset is called stock. Let us first consider the basic asset that delivers a single payoff, that is $D_{i v_{t+h}}$, on date $t+h$. It can be seen that the latter basic asset is close to the bond indexed on nominal GDP studied earlier. The difference is that the nominal GDP-indexed bond had an expected real payoff of one unit, while the present basic asset has an expected payoff of:

$$
\mathbb{E}_{t}\left(\frac{\operatorname{Div}_{t+h}}{\operatorname{Div}_{t}}\right)=\exp \left(h\left[\overline{d i v}+\log \mathbb{E}\left(\exp \left[\rho_{d} v\right]\right)+\frac{\sigma_{d}^{2}}{2}\right]\right)
$$

Therefore, denoting by $P_{t, h}^{d}$ the price of the basic asset, it comes that $P_{t, h}^{d}=\operatorname{Div}_{t} F_{h}^{d^{\prime}} z_{t}$, with:

$$
F_{h}^{d}=J^{h} \mathbf{1}
$$


where

$$
J=\exp \left(\overline{\operatorname{div}}+\frac{\sigma_{d}^{2}}{2}\right)\left(\exp \left[\left(-\mu_{r}-\frac{(1-\phi) \rho_{d} \bar{s}}{\lambda}-\rho_{d} \phi \frac{\mu}{\lambda}\right) \mathbf{1}^{\prime}+\frac{\rho_{d}}{\lambda} \mu^{\prime}\right] \odot Q\right) .
$$

As a consequence, under a no-bubble transversality condition, the stock price is given by:

$$
P_{t}^{d}=\operatorname{Div}_{t} \sum_{h=1}^{+\infty}\left(J^{h} \mathbf{1}\right)^{\prime} z_{t}=\operatorname{Div}_{t} \mathbf{1}^{\prime} J^{\prime}\left(I d-J^{\prime}\right)^{-1} z_{t}
$$

Hence:

$$
\frac{P_{t}^{d}}{\operatorname{Div}_{t}}=[\underbrace{(I d-J)^{-1} J \mathbf{1}}_{=: \chi}]^{\prime} z_{t}
$$

We have:

$$
\begin{aligned}
& \frac{P_{t+1}^{d}+\operatorname{Div}_{t+1}}{P_{t}^{d}}-1 \\
= & \frac{P_{t+1}^{d}}{\operatorname{Div}_{t+1}} \frac{\operatorname{Div}_{t+1}}{\operatorname{Div}_{t}} \frac{\operatorname{Div}_{t}}{P_{t}^{d}}+\frac{\operatorname{Div}_{t+1}}{\operatorname{Div}_{t}} \frac{\operatorname{Div}_{t}}{P_{t}^{d}}-1 \\
= & \frac{\operatorname{Div}_{t+1}}{\operatorname{Div}_{t}} \frac{\operatorname{Div}_{t}}{P_{t}^{d}}\left(1+\frac{P_{t+1}^{d}}{\operatorname{Div}_{t+1}}\right)-1 \\
= & \exp \left[\overline{\operatorname{div}}+\rho_{d} v_{t+1}+\varepsilon_{t+1}^{d}\right] \frac{C_{t}}{P_{t}^{d}}\left(1+\frac{P_{t+1}^{d}}{C_{t+1}}\right)-1 \\
= & \exp \left[\frac{\rho_{d}}{\lambda^{\prime} z_{t}}\left(\mu^{\prime} z_{t+1}-(1-\phi) \bar{s}-\phi \mu^{\prime} z_{t}\right)+\overline{d i v}+\varepsilon_{t+1}^{d}\right]\left[\left(\frac{1}{\chi}\right)^{\prime} z_{t}\right]\left(1+\chi^{\prime} z_{t+1}\right)-1 \\
= & \exp \left(\overline{d i v}+\varepsilon_{t+1}^{d}\right) z_{t}^{\prime}\left\{\exp \left[\frac{1}{\lambda} \mu^{\prime}-\left(\frac{(1-\phi) \bar{s}}{\lambda}+\phi \frac{\mu}{\lambda}\right) \mathbf{1}^{\prime}\right] \odot \frac{\mathbf{1}^{\prime}+\chi^{\prime}}{\chi}\right\} z_{t+1}-1 \\
= & : \exp \left(\varepsilon_{t+1}^{d}-\frac{\sigma_{d}^{2}}{2}\right) z_{t}^{\prime} M z_{t+1}-1 .
\end{aligned}
$$

where

$$
M=\exp \left(\overline{\operatorname{div}}+\frac{\sigma_{d}^{2}}{2}\right)\left\{\exp \left[\frac{1}{\lambda} \mu^{\prime}-\left(\frac{(1-\phi) \bar{s}}{\lambda}+\phi \frac{\mu}{\lambda}\right) \mathbf{1}^{\prime}\right] \odot \frac{\mathbf{1}^{\prime}+\chi^{\prime}}{\chi}\right\} .
$$

Therefore:

$$
\begin{aligned}
\mathbb{E}_{t}\left(\frac{P_{t+1}^{d}+D i v_{t+1}}{P_{t}^{d}}-1\right) & =\mathbb{E}_{t}\left(z_{t}^{\prime} M z_{t+1}-1\right) \\
& =z_{t} M \Pi^{\prime} z_{t}-1=\operatorname{diag}\left(M \Pi^{\prime}\right)^{\prime} z_{t}-1 \\
& =[(M \odot \Pi) \mathbf{1}]^{\prime} z_{t}-1 \\
& =\mathbf{1}^{\prime}(M \odot \Pi)^{\prime} z_{t}-1,
\end{aligned}
$$


and

$$
\begin{aligned}
\mathbb{E}\left(\frac{P_{t+1}^{d}+D i v_{t+1}}{P_{t}^{d}}-1\right) & =\mathbb{E}\left(\mathbf{1}^{\prime}(M \odot \Pi)^{\prime} z_{t}-1\right) \\
& =\mathbf{1}^{\prime}(M \odot \Pi)^{\prime} \mathbb{E}\left(z_{t}\right)-1 .
\end{aligned}
$$

Consider a $h$-period stock investment. Assuming that dividend proceeds are reinvested in the same stock, the $h$-period return reads:

$$
\begin{aligned}
R_{t, t+h}= & \frac{P_{t+1}^{d}+C_{t+1}}{P_{t}^{d}} \frac{P_{t+2}^{d}+C_{t+2}}{P_{t+1}^{d}} \times \cdots \times \frac{P_{t+h}^{d}+C_{t+h}}{P_{t+h-1}^{d}}-1 \\
= & \left(z_{t}^{\prime} M z_{t+1}\right) \times\left(z_{t+1}^{\prime} M z_{t+2}\right) \times \cdots \times\left(z_{t+h-1}^{\prime} M z_{t+h}\right) \times \\
& \exp \left(\varepsilon_{t+1}^{d}+\cdots+\varepsilon_{t+h}^{d}-h \frac{\sigma_{d}^{2}}{2}\right)-1 .
\end{aligned}
$$

$$
\begin{aligned}
\mathbb{E}_{t}\left(R_{t, t+h}\right) & =\mathbb{E}_{t}\left[\left(z_{t}^{\prime} M z_{t+1}\right) \times\left(z_{t+1}^{\prime} M z_{t+2}\right) \times \cdots \times\left(z_{t+h-1}^{\prime} M z_{t+h}\right)\right]-1 \\
& =\mathbb{E}_{t}\left(\mathbb{E}_{t+h-1}\left[\left(z_{t}^{\prime} M z_{t+1}\right) \times\left(z_{t+1}^{\prime} M z_{t+2}\right) \times \cdots \times\left(z_{t+h-1}^{\prime} M z_{t+h}\right)\right]\right)-1 \\
& =\mathbb{E}_{t}\left(\left(z_{t}^{\prime} M z_{t+1}\right) \times \cdots \times\left(z_{t+h-2}^{\prime} M z_{t+h-1}\right) z_{t+h-1}^{\prime} M \mathbb{E}_{t+h-1}\left[z_{t+h}\right]\right)-1 \\
& =\mathbb{E}_{t}\left[\left(z_{t}^{\prime} M z_{t+1}\right) \times \cdots \times\left(z_{t+h-2}^{\prime} M z_{t+h-1}\right) z_{t+h-1}^{\prime} M \Pi^{\prime} z_{t+h-1}\right]-1 \\
& =\mathbb{E}_{t}\left[\left(z_{t}^{\prime} M z_{t+1}\right) \times \ldots z_{t+h-3}^{\prime} M z_{t+h-2} z_{t+h-2}^{\prime} M \operatorname{Diag}\left[\operatorname{diag}\left(M \Pi^{\prime}\right)\right] \Pi^{\prime} z_{t+h-2}\right]-1 \\
& =\mathbb{E}_{t}\left[\left(z_{t}^{\prime} M z_{t+1}\right) \times \ldots z_{t+h-3}^{\prime} M \operatorname{Diag}\left[\operatorname{diag}\left(M \operatorname{Diag}\left[\operatorname{diag}\left(M \Pi^{\prime}\right)\right] \Pi^{\prime}\right)\right] \Pi^{\prime} z_{t+h-3}\right]-1 \\
& =z_{t}^{\prime} H_{h} z_{t}-1 \\
& =\left(\operatorname{diag} H_{h}\right)^{\prime} z_{t}-1 \\
& =E_{h}^{\prime} z_{t}
\end{aligned}
$$

where $H_{0}=I d$ and

$$
H_{h}=M \operatorname{Diag}\left[\operatorname{diag}\left(H_{h-1}\right)\right] \Pi^{\prime},
$$

for $h>1$. 


$$
\begin{aligned}
& V_{h}^{\prime} z_{t}:=\operatorname{Var}_{t}\left[\left(z_{t}^{\prime} M z_{t+1}\right) \times\left(z_{t+1}^{\prime} M z_{t+2}\right) \times \cdots \times\left(z_{t+h-1}^{\prime} M z_{t+h}\right)\right] \\
& =\mathbb{E}_{t}\left(\mathbb{V a r}_{t+1}\left[\left(z_{t}^{\prime} M z_{t+1}\right) \times\left(z_{t+1}^{\prime} M z_{t+2}\right) \times \cdots \times\left(z_{t+h-1}^{\prime} M z_{t+h}\right)\right]\right)+ \\
& \operatorname{Var}_{t}\left(\mathbb{E}_{t+1}\left[\left(z_{t}^{\prime} M z_{t+1}\right) \times\left(z_{t+1}^{\prime} M z_{t+2}\right) \times \cdots \times\left(z_{t+h-1}^{\prime} M z_{t+h}\right)\right]\right) \\
& =\mathbb{E}_{t}\left(\left(z_{t}^{\prime} M z_{t+1}\right)^{2} V_{h}^{\prime} z_{t+1}\right)+\operatorname{Var}_{t}\left(\left(z_{t}^{\prime} M z_{t+1}\right)\left(\operatorname{diag} H_{h-1}\right)^{\prime} z_{t+1}\right) \\
& =z_{t}^{\prime}\left[(M \odot M) \odot \mathbf{1} V_{h-1}^{\prime}\right] \Pi^{\prime} z_{t}+\mathbb{V a r} t\left(\left(z_{t}^{\prime} M z_{t+1}\right)\left(\operatorname{diag} H_{h-1}\right)^{\prime} z_{t+1}\right) \\
& =\operatorname{diag}\left(\left[(M \odot M) \odot \mathbf{1} V_{h-1}^{\prime}\right] \Pi^{\prime}\right)^{\prime} z_{t}+\operatorname{Var}_{t}(z_{t}^{\prime} \underbrace{\left(M \odot \mathbf{1}\left[\operatorname{diag} H_{h-1}\right]^{\prime}\right)}_{=: A_{h-1}} z_{t+1}) \\
& =\operatorname{diag}\left(\left[(M \odot M) \odot \mathbf{1} V_{h-1}^{\prime}\right] \Pi^{\prime}+\Pi\left(A_{h-1} \odot A_{h-1}\right)-\left\{\left(\Pi A_{h-1}\right) \odot\left(\Pi A_{h-1}\right)\right\}\right)^{\prime} z_{t} .
\end{aligned}
$$

Using eq. (oa.5), we obtain:

$$
\begin{aligned}
\operatorname{Var}_{t}\left(R_{t, t+h}\right) & =\exp \left(h \sigma_{d}^{2}\right) V_{h}^{\prime} z_{t}+\left[\exp \left(h \sigma_{d}^{2}\right)-1\right]\left(E_{h}^{\prime} z_{t}\right)^{2} \\
& =\left\{\exp \left(h \sigma_{d}^{2}\right) V_{h}+\left[\exp \left(h \sigma_{d}^{2}\right)-1\right]\left(E_{h} \odot E_{h}\right)\right\}^{\prime} z_{t} .
\end{aligned}
$$

\section{APPENDIX II. SECOND-ORDER MOMENTS OF $\pi_{t}$ AND $z_{t}$}

The discretized version of the consumption innovations $v_{t}$ is:

$$
\begin{aligned}
c_{t+1}-\mathbb{E}_{t}\left(c_{t+1}\right) & =\frac{1}{\lambda^{\prime} z_{t}}\left(\mu^{\prime} z_{t+1}-(1-\phi) \bar{s}-\phi \mu^{\prime} z_{t}\right) \\
& =z_{t}^{\prime} \underbrace{\left[\frac{\mu^{\prime}}{\lambda}-(1-\phi) \bar{s} \frac{\mathbf{1}^{\prime}}{\lambda}-\phi \frac{\mu}{\lambda} \mathbf{1}^{\prime}\right]}_{=: B} z_{t+1} .
\end{aligned}
$$

Using eq. (oa.4), we obtain:

$$
\begin{aligned}
& \operatorname{Var}\left[c_{t+1}-\mathbb{E}_{t}\left(c_{t+1}\right)\right]= \mathbb{V a r}\left[z_{t}^{\prime} B z_{t+1}\right] \\
&= {[(B \odot \Pi) \mathbf{1}]^{\prime} \mathbb{V a r}\left(z_{t}\right)[(B \odot \Pi) \mathbf{1}]+} \\
& \operatorname{diag}[\Pi(B \odot B)-\{(\Pi B) \odot(\Pi B)\}]^{\prime} \mathbb{E}\left(z_{t}\right) . \\
& \mathbb{E}_{t}\left(\left[\begin{array}{c}
\pi_{t+1} \\
z_{t+1}
\end{array}\right]\right)=\left[\begin{array}{c}
\bar{\pi}+\psi\left(\pi_{t}-\bar{\pi}\right) \\
\Pi^{\prime} z_{t}
\end{array}\right]=\left[\begin{array}{c}
(1-\psi) \bar{\pi} \\
0
\end{array}\right]+\underbrace{\left[\begin{array}{cc}
\psi & 0 \\
0 & \Pi^{\prime}
\end{array}\right]}_{=: \Phi}\left[\begin{array}{c}
\pi_{t} \\
z_{t}
\end{array}\right]
\end{aligned}
$$




$$
\begin{aligned}
\operatorname{Var}_{t}\left(\left[\begin{array}{l}
\pi_{t+1} \\
z_{t+1}
\end{array}\right]\right) & =\operatorname{Var}_{t}\left(\left[\begin{array}{c}
\varepsilon^{\pi}{ }_{t+1}+\rho_{\pi} z_{t}^{\prime} B z_{t+1} \\
z_{t+1}
\end{array}\right]\right) \\
& =\left[\begin{array}{cc}
\sigma_{\pi}^{2} & 0 \\
0 & 0
\end{array}\right]+\mathbb{V a r}\left(\left[\begin{array}{c}
\rho_{\pi} z_{t}^{\prime} B \\
I d
\end{array}\right] z_{t+1}\right) \\
= & {\left[\begin{array}{cc}
\sigma_{\pi}^{2} & 0 \\
0 & 0
\end{array}\right]+\left[\begin{array}{c}
z_{t}^{\prime} \rho_{\pi} B \\
I d
\end{array}\right]\left[\operatorname{Diag}\left(\Pi^{\prime} z_{t}\right)-\Pi^{\prime} z_{t} z_{t}^{\prime} \Pi\right]\left[\begin{array}{c}
z_{t}^{\prime} \rho_{\pi} B \\
I d
\end{array}\right]^{\prime} } \\
= & {\left[\begin{array}{cc}
\sigma_{\pi}^{2} & 0 \\
0 & 0
\end{array}\right]+\left[\begin{array}{cc}
\rho_{\pi}^{2} z_{t}^{\prime} B\left[\operatorname{Diag}\left(\Pi^{\prime} z_{t}\right)-\Pi^{\prime} z_{t} z_{t}^{\prime} \Pi\right] B^{\prime} z_{t} & \rho_{\pi} z_{t}^{\prime} B\left[\operatorname{Diag}\left(\Pi^{\prime} z_{t}\right)-\Pi^{\prime} z_{t} z_{t}^{\prime} \Pi\right] \\
\rho_{\pi}\left[\operatorname{Diag}\left(\Pi^{\prime} z_{t}\right)-\Pi^{\prime} z_{t} z_{t}^{\prime} \Pi\right] B^{\prime} z_{t} & {\left[\operatorname{Diag}\left(\Pi^{\prime} z_{t}\right)-\Pi^{\prime} z_{t} z_{t}^{\prime} \Pi\right]}
\end{array}\right] . }
\end{aligned}
$$

We have:

$$
\begin{aligned}
z_{t}^{\prime} B\left[\operatorname{Diag}\left(\Pi^{\prime} z_{t}\right)-\Pi^{\prime} z_{t} z_{t}^{\prime} \Pi\right] B^{\prime} z_{t} & =z_{t}^{\prime} B \operatorname{Diag}\left(\Pi^{\prime} z_{t}\right) B^{\prime} z_{t}-z_{t}^{\prime} B \Pi^{\prime} z_{t} z_{t}^{\prime} \Pi B^{\prime} z_{t} \\
& =\left[(B \odot B) \Pi^{\prime} z_{t}\right]^{\prime} z_{t}-\left[\left(B \Pi^{\prime} \odot B \Pi^{\prime}\right) z_{t}\right]^{\prime} z_{t} \\
& =z_{t}^{\prime} \Pi\left(B^{\prime} \odot B^{\prime}\right) z_{t}-z_{t}^{\prime}\left(\Pi B^{\prime} \odot \Pi B^{\prime}\right) z_{t} \\
& =\operatorname{diag}\left[\Pi\left(B^{\prime} \odot B^{\prime}\right)-\Pi B^{\prime} \odot \Pi B^{\prime}\right]^{\prime} z_{t} \\
{\left[\operatorname{Diag}\left(\Pi^{\prime} z_{t}\right)-\Pi^{\prime} z_{t} z_{t}^{\prime} \Pi\right] B^{\prime} z_{t} } & =\left(\Pi^{\prime} \odot B^{\prime}\right) z_{t}-\Pi^{\prime} z_{t} \operatorname{diag}\left(\Pi B^{\prime}\right)^{\prime} z_{t} \\
& =\left(\Pi^{\prime} \odot B^{\prime}\right) z_{t}-\left(\Pi^{\prime} \odot \mathbf{1 d i a g}\left(\Pi B^{\prime}\right)^{\prime}\right) z_{t} \\
& =\left(\Pi^{\prime} \odot B^{\prime}\right) z_{t}-\left(\Pi^{\prime} \odot \mathbf{1}[(\Pi \odot B) \mathbf{1}]^{\prime}\right) z_{t} \\
& =\left(\Pi^{\prime} \odot B^{\prime}\right) z_{t}-\left[\Pi^{\prime} \odot \mathbf{1} \mathbf{1}^{\prime}\left(\Pi^{\prime} \odot B^{\prime}\right)\right] z_{t}
\end{aligned}
$$

and

$$
\operatorname{Diag}\left(\Pi^{\prime} z_{t}\right)-\Pi^{\prime} z_{t} z_{t}^{\prime} \Pi=\operatorname{Diag}\left(\Pi^{\prime} z_{t}\right)-\Pi^{\prime} \operatorname{Diag}\left(z_{t}\right) \Pi
$$

Therefore: 


$$
\begin{aligned}
\operatorname{Var}_{t}\left(\left[\begin{array}{c}
\pi_{t+1} \\
z_{t+1}
\end{array}\right]\right)= & {\left[\begin{array}{cc}
\sigma_{\pi}^{2} & 0 \\
0 & 0
\end{array}\right]+} \\
& {\left[\begin{array}{cc}
\rho_{\pi}^{2} \operatorname{diag}\left[\Pi\left(B^{\prime} \odot B^{\prime}\right)-\Pi B^{\prime} \odot \Pi^{\prime}\right]^{\prime} z_{t} & \rho_{\pi} z_{t}^{\prime}\left[\Pi^{\prime} \odot B^{\prime}-\Pi^{\prime} \odot \mathbf{1 1}^{\prime}\left(\Pi^{\prime} \odot B^{\prime}\right)\right]^{\prime} \\
\rho_{\pi}\left[\Pi^{\prime} \odot B^{\prime}-\Pi^{\prime} \odot \mathbf{1 1}^{\prime}\left(\Pi^{\prime} \odot B^{\prime}\right)\right] z_{t} & \operatorname{Diag}\left(\Pi^{\prime} z_{t}\right)-\Pi^{\prime} \operatorname{Diag}\left(z_{t}\right) \Pi
\end{array}\right] } \\
=: & G\left(z_{t}\right) .
\end{aligned}
$$

Let us define $\Omega=G\left(\mathbb{E}\left(z_{t}\right)\right)$. Because $\left[\pi_{t}, z_{t}^{\prime}\right]^{\prime}$ is affine, we have that:

$$
\operatorname{Var}\left(\left[\begin{array}{l}
\pi_{t} \\
z_{t}
\end{array}\right]\right)=\Omega+\Phi \Omega \Phi^{\prime}+\cdots+\Phi^{k} \Omega \Phi^{k^{\prime}}+\ldots
$$

It is easily seen that:

$$
\Phi^{k}=\left[\begin{array}{cc}
\psi^{k} & 0 \\
0 & \left(\Pi^{\prime}\right)^{k}
\end{array}\right]
$$

and, therefore, that:

$$
\Phi^{k} \Omega \Phi^{k^{\prime}}=\left[\begin{array}{ll}
\Omega_{11, k} & \Omega_{21, k}^{\prime} \\
\Omega_{21, k} & \Omega_{22, k}^{\prime}
\end{array}\right]
$$

with

$$
\begin{aligned}
\Omega_{11, k} & =\psi^{2^{k}}\left\{\sigma_{\pi}^{2}+\rho_{\pi}^{2} \operatorname{diag}\left[\Pi\left(B^{\prime} \odot B^{\prime}\right)-\Pi B^{\prime} \odot \Pi B^{\prime}\right]^{\prime} \mathbb{E}\left(z_{t}\right)\right\} \\
\Rightarrow \operatorname{Var}\left(\pi_{t}\right) & =\frac{\sigma_{\pi}^{2}+\rho_{\pi}^{2} \operatorname{diag}\left[\Pi\left(B^{\prime} \odot B^{\prime}\right)-\Pi B^{\prime} \odot \Pi B^{\prime}\right]^{\prime} \mathbb{E}\left(z_{t}\right)}{1-\psi^{2}}
\end{aligned}
$$

and

$$
\begin{aligned}
\Omega_{21, k} & =\rho_{\pi} \psi^{k} \Pi^{\prime k}\left[\Pi^{\prime} \odot B^{\prime}-\Pi^{\prime} \odot \mathbf{1 1}^{\prime}\left(\Pi^{\prime} \odot B^{\prime}\right)\right] \mathbb{E}\left(z_{t}\right) \\
\Rightarrow \operatorname{Cov}\left(\pi_{t}, z_{t}\right) & =\rho_{\pi}\left(I d-\psi \Pi^{\prime}\right)^{-1}\left[\Pi^{\prime} \odot B^{\prime}-\Pi^{\prime} \odot \mathbf{1 1}^{\prime}\left(\Pi^{\prime} \odot B^{\prime}\right)\right] \mathbb{E}\left(z_{t}\right) .
\end{aligned}
$$

It is easily shown that:

$$
\begin{gathered}
\operatorname{Cov}\left(\left[\begin{array}{l}
\pi_{t} \\
z_{t}
\end{array}\right],\left[\begin{array}{l}
\pi_{t-1} \\
z_{t-1}
\end{array}\right]\right)=\Phi \mathbb{V a r}\left(\left[\begin{array}{l}
\pi_{t} \\
z_{t}
\end{array}\right]\right) \cdot \\
{\left[\begin{array}{c}
\pi_{t} \\
\Delta y_{t} \\
\Delta c_{t}
\end{array}\right]=\operatorname{sst}+\underbrace{\left[\begin{array}{lll}
\psi & 0 & 0 \\
0 & 0 & 0 \\
0 & 0 & 0
\end{array}\right]}_{=: \Phi}\left[\begin{array}{c}
\pi_{t-1} \\
\Delta y_{t-1} \\
\Delta c_{t-1}
\end{array}\right]+\underbrace{\left[\begin{array}{lll}
1 & 0 & \rho_{\pi} \\
0 & 1 & \rho_{y} \\
0 & 0 & 1
\end{array}\right]}_{=\Sigma}\left[\begin{array}{c}
\varepsilon^{\pi} t \\
\varepsilon^{y} t \\
v_{t}
\end{array}\right]}
\end{gathered}
$$




$$
\operatorname{vec} \mathbb{V a r}\left(\left[\begin{array}{c}
\pi_{t} \\
\Delta y_{t} \\
\Delta c_{t}
\end{array}\right]\right)=\left(I d_{9 \times 9}-\Phi \otimes \Phi\right) \operatorname{vec}\left(\Sigma \operatorname{diag}\left(\left[\sigma_{\pi}^{2}, \sigma_{y}^{2}, \mathbb{V a r}\left(v_{t}\right)\right]^{\prime}\right) \Sigma^{\prime}\right)
$$

\section{APPENDIX III. USEFUL FORMULAS}

This appendix provides a battery of formulas to compute first- and second-order conditional and unconditional moments used in our calibration process. The dynamics of $z_{t}$ is as defined in Appendix A.1.

$$
\begin{aligned}
\operatorname{Var}_{t}\left(a^{\prime} z_{t+1}\right) & =a^{\prime} \mathbb{V a r}\left(z_{t+1}\right) a=a^{\prime}\left(\mathbb{E}_{t}\left(z_{t+1} z_{t+1}^{\prime}\right)-\mathbb{E}_{t}\left(z_{t+1}\right) \mathbb{E}_{t}\left(z_{t+1}\right)^{\prime}\right) a \\
& =[\Pi(a \odot a)]^{\prime} z_{t}-a^{\prime} \Pi^{\prime} z_{t} z_{t}^{\prime} \Pi a \\
& =[\Pi(a \odot a)]^{\prime} z_{t}-z_{t}^{\prime} \Pi a a^{\prime} \Pi^{\prime} z_{t} \\
& =[\Pi(a \odot a)]^{\prime} z_{t}-\operatorname{diag}\left(\Pi a a^{\prime} \Pi^{\prime}\right)^{\prime} z_{t} \\
& =[\Pi(a \odot a)]^{\prime} z_{t}-([\Pi a] \odot[\Pi a])^{\prime} z_{t} \\
& =[\Pi(a \odot a)-(\Pi a) \odot(\Pi a)]^{\prime} z_{t} .
\end{aligned}
$$

If $a=A z_{t}$ :

$$
\begin{gathered}
a a^{\prime}=A z_{t} z_{t}^{\prime} A^{\prime} \\
\mathbb{V a r}_{t}\left(z_{t}^{\prime} A z_{t+1}\right)=\left[\Pi(A \odot A) z_{t}-\{(\Pi A) \odot(\Pi A)\} z_{t}\right]^{\prime} z_{t} \\
=z_{t}^{\prime}[\Pi(A \odot A)-\{(\Pi A) \odot(\Pi A)\}] z_{t} \\
=\operatorname{diag}[\Pi(A \odot A)-\{(\Pi A) \odot(\Pi A)\}]^{\prime} z_{t} . \\
\mathbb{E}_{t}\left(z_{t+1} z_{t+1}^{\prime} A z_{t+1}\right)=\mathbb{E}_{t}\left(\operatorname{diag}(A) \odot z_{t+1}\right) \\
=\operatorname{diag}(A) \odot \Pi^{\prime} z_{t} \\
=\operatorname{Diag}[\operatorname{diag}(A)] \Pi^{\prime} z_{t} \\
\mathbb{E}\left(z_{t} z_{t}^{\prime}\right)=\operatorname{Diag}\left(\mathbb{E}\left(z_{t}\right)\right) \\
\mathbb{V}\left(z_{t}\right)=\operatorname{Diag}\left(\mathbb{E}\left(z_{t}\right)\right)-\mathbb{E}\left(z_{t}\right) \mathbb{E}\left(z_{t}\right)^{\prime}
\end{gathered}
$$




$$
\begin{aligned}
\operatorname{Var}\left(z_{t}^{\prime} A z_{t+1}\right)= & \mathbb{V} \operatorname{ar}\left(\mathbb{E}_{t}\left[z_{t}^{\prime} A z_{t+1}\right]\right)+\mathbb{E}\left(\mathbb{V a r} r_{t}\left[z_{t}^{\prime} A z_{t+1}\right]\right) \\
= & \mathbb{V} \operatorname{ar}\left(z_{t}^{\prime} A \Pi^{\prime} z_{t}\right)+\mathbb{E}\left(\operatorname{diag}[\Pi(A \odot A)-\{(\Pi A) \odot(\Pi A)\}]^{\prime} z_{t}\right) \\
= & \mathbb{V} \operatorname{ar}\left(\operatorname{diag}\left(A \Pi^{\prime}\right)^{\prime} z_{t}\right)+\mathbb{E}\left(\operatorname{diag}[\Pi(A \odot A)-\{(\Pi A) \odot(\Pi A)\}]^{\prime} z_{t}\right) \\
= & \mathbb{V} \operatorname{ar}\left([(A \odot \Pi) \mathbf{1}]^{\prime} z_{t}\right)+\mathbb{E}\left(\operatorname{diag}[\Pi(A \odot A)-\{(\Pi A) \odot(\Pi A)\}]^{\prime} z_{t}\right) \\
= & {[(A \odot \Pi) \mathbf{1}]^{\prime} \mathbb{V} \operatorname{ar}\left(z_{t}\right)[(A \odot \Pi) \mathbf{1}]+} \\
& \operatorname{diag}[\Pi(A \odot A)-\{(\Pi A) \odot(\Pi A)\}]^{\prime} \mathbb{E}\left(z_{t}\right) .
\end{aligned}
$$

If $X \sim \mathcal{N}\left(0, \sigma^{2}\right)$, we have:

$$
\begin{aligned}
\operatorname{Var}(\exp (X)) & =\mathbb{E}(\exp (2 X))-\mathbb{E}(\exp (X))^{2} \\
& =\exp \left(2 \sigma^{2}\right)-\exp \left(\sigma^{2}\right)
\end{aligned}
$$

$$
\operatorname{Var}\left(\exp \left(X-\sigma^{2} / 2\right)\right)=\exp \left(\sigma^{2}\right)-1
$$

$$
\begin{aligned}
\operatorname{Var}\left(\exp \left(X-\sigma^{2} / 2\right) Y\right) & =\mathbb{E}\left(\exp \left(2 X-\sigma^{2}\right) Y^{2}\right)-\mathbb{E}\left(\exp \left(X-\sigma^{2} / 2\right) Y\right)^{2} \\
& =\exp \left(\sigma^{2}\right) \mathbb{E}\left(Y^{2}\right)-\mathbb{E}(Y)^{2} \\
& =\exp \left(\sigma^{2}\right) \mathbb{V} \operatorname{ar}(Y)+\left[\exp \left(\sigma^{2}\right)-1\right] \mathbb{E}(Y)^{2}
\end{aligned}
$$




$$
\begin{aligned}
& \Psi_{t, \pi, z}(u, v) \\
= & \mathbb{E}_{t}\left[\exp \left(u \pi_{t+1}+v^{\prime} z_{t+1}\right)\right] \\
= & \mathbb{E}_{t}\left[\exp \left(u\left[\bar{\pi}(1-\psi)+\psi \pi_{t}+\varepsilon^{\pi}{ }_{t+1}+\rho_{\pi}\left(c_{t+1}-\mathbb{E}_{t}\left(c_{t+1}\right)\right)\right]+v^{\prime} z_{t+1}\right)\right] \\
= & \mathbb{E}_{t}\left[\exp \left(u\left\{\bar{\pi}(1-\psi)+\psi \pi_{t}+\varepsilon^{\pi}{ }_{t+1}+\rho_{\pi}\left[\frac{1}{\lambda^{\prime} z_{t}}\left(\mu^{\prime} z_{t+1}-(1-\phi) \bar{s}-\phi \mu^{\prime} z_{t}\right)\right]\right\}+v^{\prime} z_{t+1}\right)\right] \\
= & \exp \left(u\left[\bar{\pi}(1-\psi)+\psi \pi_{t}\right]+\frac{u^{2} \sigma_{\pi}^{2}}{2}\right) \mathbb{E}_{t}\left[\exp \left(\frac{u \rho_{\pi}}{\lambda^{\prime} z_{t}}\left[\mu^{\prime} z_{t+1}-(1-\phi) \bar{s}-\phi \mu^{\prime} z_{t}\right]+v^{\prime} z_{t+1}\right)\right] \\
= & \exp \left(u\left[\bar{\pi}(1-\psi)+\psi \pi_{t}\right]+\frac{u^{2} \sigma_{\pi}^{2}}{2}\right) \mathbb{E}_{t}\left[z_{t}^{\prime} \exp \left(u \rho_{\pi}\left[\frac{\mu^{\prime}}{\lambda}-(1-\phi) \bar{s} \frac{\mathbf{1}^{\prime}}{\lambda}-\phi \frac{\mu}{\lambda} \mathbf{1}^{\prime}\right]+\mathbf{1}^{\prime}\right) z_{t+1}\right] \\
= & \exp \left(u\left[\bar{\pi}(1-\psi)+\psi \pi_{t}\right]+\frac{u^{2} \sigma_{\pi}^{2}}{2}\right) z_{t}^{\prime} \exp \left(u \rho_{\pi}\left[\frac{\mu^{\prime}}{\lambda}-(1-\phi) \bar{s} \frac{\mathbf{1}^{\prime}}{\lambda}-\phi \frac{\mu}{\lambda} \mathbf{1}^{\prime}\right]+\mathbf{1} v^{\prime}\right) \Pi^{\prime} z_{t} \\
= & \exp \left(u\left[\bar{\pi}(1-\psi)+\psi \pi_{t}\right]+\frac{u^{2} \sigma_{\pi}^{2}}{2}\right) \operatorname{diag}\left[\exp \left(u \rho_{\pi}\left[\frac{\mu^{\prime}}{\lambda}-(1-\phi) \bar{s} \frac{\mathbf{1}^{\prime}}{\lambda}-\phi \frac{\mu}{\lambda} \mathbf{1}^{\prime}\right]+\mathbf{1}^{\prime}\right) \Pi^{\prime}\right]^{\prime} z_{t} \\
= & \exp \left(u\left[\bar{\pi}(1-\psi)+\psi \pi_{t}\right]+\frac{u^{2} \sigma_{\pi}^{2}}{2}\right)\left[\left\{\exp \left(u \rho_{\pi}\left[\frac{\mu^{\prime}}{\lambda}-(1-\phi) \bar{s} \frac{\mathbf{1}^{\prime}}{\lambda}-\phi \frac{\mu}{\lambda} \mathbf{1}^{\prime}\right]+\mathbf{1} v^{\prime}\right) \odot \Pi\right\}^{\prime}\right]_{t}^{\prime} z_{t} \\
= & \exp \left(u\left[\bar{\pi}(1-\psi)+\psi \pi_{t}\right]+\frac{u^{2} \sigma_{\pi}^{2}}{2}\right. \\
& \left.+\log \left[\left\{\exp \left(u \rho_{\pi}\left[\frac{\mu^{\prime}}{\lambda}-(1-\phi) \bar{s} \frac{\mathbf{1}^{\prime}}{\lambda}-\phi \frac{\mu}{\lambda} \mathbf{1}^{\prime}\right]+\mathbf{1} v^{\prime}\right) \odot \Pi\right\}\right]^{\prime} z_{t}\right) \\
= & \exp \left[a(u) \pi t+d(u, v)^{\prime} z_{t}\right],
\end{aligned}
$$

where

$$
\left\{\begin{aligned}
a(u)= & u \psi \\
d(u, v)= & u \bar{\pi}(1-\psi)+\frac{u^{2} \sigma_{\pi}^{2}}{2}+ \\
& \log \left[\left\{\exp \left(u \rho_{\pi}\left[\frac{\mu^{\prime}}{\lambda}-(1-\phi) \bar{s} \frac{\mathbf{1}^{\prime}}{\lambda}-\phi \frac{\mu}{\lambda} \mathbf{1}^{\prime}\right]+\mathbf{1} v^{\prime}\right) \odot \Pi\right\} \mathbf{1}\right] .
\end{aligned}\right.
$$

APPENDIX V. GDP FORECASTS

$$
\exp \left(h y_{t, h}^{e}\right)=\mathbb{E}_{t}\left(\frac{G D P_{t+h}}{G D P_{t}}\right)=\exp \left(h y_{t, t+h}\right)
$$




$$
\begin{aligned}
\mathbb{E}_{t}\left(\frac{G D P_{t+h}}{G D P_{t}}\right) & =\mathbb{E}_{t}\left(\exp \left[h g_{y}+\rho_{y}\left(v_{t+1}+\cdots+v_{t+h}\right)+\varepsilon_{t+1}^{y}+\cdots+\varepsilon_{t+h}^{y}\right]\right) \\
& \left.=\exp \left[h\left(g_{y}+\frac{\sigma_{y}^{2}}{2}\right)\right]\left[\mathbb{E}\left(\exp \left[\rho_{y} v\right)\right]\right)\right]^{h} \\
& =\exp \left[h\left(g_{y}+\frac{\sigma_{y}^{2}}{2}\right)\right]\left[\operatorname{diag}\left(\exp \left[\rho_{y} B\right] \Pi^{\prime}\right)^{\prime} \mathbb{E}\left(z_{t}\right)\right]^{h} .
\end{aligned}
$$

where $B$ is defined in eq. (oa.3).

Therefore:

$$
\left.y_{t, h}^{e}=g_{y}+\frac{\sigma_{y}^{2}}{2}+\log \mathbb{E}\left(\exp \left[\rho_{y} v\right)\right]\right) .
$$

